\title{
Anticancer and Anti-Inflammatory Activities of Some New Pyrazolo[3,4-b]pyrazines
}

\author{
Hussein El-Kashef ${ }^{1, *}$, Talaat El-Emary ${ }^{1}$, Pierre Verhaeghe ${ }^{2}$, Patrice Vanelle ${ }^{3}$ and Maha Samy ${ }^{1}$ \\ 1 Chemistry Department, Faculty of Science, Assiut University, 71516 Assiut, Egypt; \\ emarytalaat@yahoo.com (T.E.-E.); maha11292@yahoo.com (M.S.) \\ 2 LCC-CNRS Université de Toulouse, CNRS, UPS, 205 Route de Narbonne, 3107 Toulouse, France; \\ pierre.verhaeghe@lcc-toulouse.fr \\ 3 Aix-Marseille Université, CNRS, Institut de Chimie Radicalaire ICR, UMR 7273, \\ Laboratoire de Pharmaco-Chimie Radicalaire, Faculté de Pharmacie, 27 Boulevard Jean Moulin CS 30064, \\ 13385 Marseille CEDEX 05, France; patrice.vanelle@univ-amu.fr \\ * Correspondence: elkashef@aun.edu.eg; Tel.: +20-1005075881
}

Received: 8 August 2018; Accepted: 3 September 2018; Published: 16 October 2018

\begin{abstract}
New derivatives of pyrazolo[3,4-b]pyrazines and related heterocycles were synthesized using 5-amino-3-methyl-4-nitroso-1-phenyl-pyrazole (1) as a starting material. The 5-acetyl derivative 15 was shown to be a useful key intermediate for the synthesis of several derivatives of pyrazolopyrazines. Some of the prepared compounds were evaluated for their anti-inflammatory and anti-breast cancer MCF-7 cell line activities. SAR study showed that compounds $\mathbf{1 5}$ and $\mathbf{2 9}$ exhibited remarkable anti-inflammatory activity, where $\mathbf{1 5}$ showed the same activity as that of the reference drug indomethacin. On the other hand, compounds $25 \mathbf{i}, \mathbf{2 5 j}$ showed very significant inhibitory activity $(p<0.001)$ against MCF-7 breast cancer cell line.
\end{abstract}

Keywords: pyrazolo[3,4-b]pyrazines; $o$-aminonitrosopyrazole; anticancer; anti-inflammatory; anti-breast cancer

\section{Introduction}

Although pyrazolo[3,4-b]pyrazines are not highly sited in the literature, they proved to be an interesting class of pyrazolopyrazine heterocyles. Therapeutic importance has been reported for these heterocycles, such as their use for the treatment and/or prevention of a wide variety of diseases related to adenosine receptors, depression, anxiety, Parkinson's disease, pain, dementia, heart failure, and cerebrovascular disease [1-3].

They are also used as therapeutic agents for periodontosis, hypercalcemia, osteoporosis, rheumatoid arthritis, Paget's disease, and as bone metabolism improvers [4]. Some reports indicated their use as blood platelet aggregation inhibitors [5], anti-inflammatories [6], in controlling herbicides [7], and anticancer agents with low toxicity [8,9]. In the domain of dye chemistry, they are used as fluorescent [10] and disperse dyes [11]. Certain derivatives were reported to possess antiviral, antineoplastic, antiparasitic, and anti-fungal properties [12-15]. Others showed anticonvulsant [16] and antibacterial activities $[17,18]$. Certain derivatives are useful for the treatment of hematologic diseases [19], also for the prophylaxis and treatment of protein kinase-mediated diseases, including inflammation and other related diseases. They are also used for the treatment of p38 map kinase-mediated diseases including rheumatoid arthritis, psoriasis, chronic obstructive pulmonary disease, pain, and other inflammatory disorders [20]. A microwave-assisted synthesis of fused pyrazolo[3,4-b]pyrazines via the reaction of $o$-aminonitrosopyrazoles with cyclic $\beta$-diketones was also reported [21]. 
In continuation with our interest in the synthesis of pyrazolo[3,4-b]pyrazins $[5,12,13,16-18]$, we report herein the synthesis of other derivatives and related heterocycles. Certain newly synthesized derivatives were screened for their anti-inflammatory and and anti-breast cancer MCF-7 cell line activities.

\section{Results}

\subsection{Chemistry}

In a preceding paper of our group [18], we have described the first synthesis of 3-methyl-1-phenyl$1 H$-indeno[2,1-e]pyrazolo[3,4-b]pyrazin-5-one (5). The synthetic route for this compound involved the use of $o$-aminonitrosopyrazole $\mathbf{1}$ as a starting material, which was reacted with the active methylene benzoylacetonitrile to give 2 . Hydrolysis of the cyano group of the latter compound gave the carboxylic acid 3, which was converted into the acid chloride 4, followed by intramolecular Friedel-Crafts cyclization giving 5 (Scheme 1).

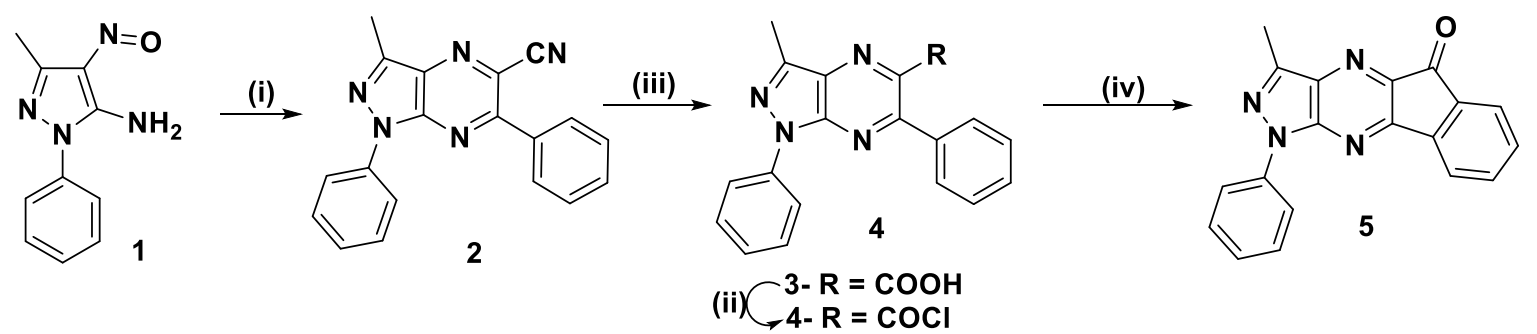

Scheme 1. Synthesis of compound 5. Reagents and conditions: (i) Benzoylacetonitrile, pyridine, reflux

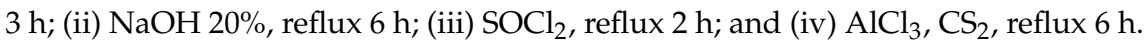

In the present work, when $o$-aminonitrosopyrazole 1 was reacted with ethyl cyanoacetate in refluxing pyridine, the expected reaction product could be either $\mathbf{6 a}$ or $\mathbf{6 b}$ (Scheme 2). The structure $\mathbf{6 b}$ was immediately ruled out by examining the ir spectrum of the product, which showed no bands corresponding to $-\mathrm{NH}_{2}$ and -COOEt groups. However, the spectrum showed two bands at 3197 and $2254 \mathrm{~cm}^{-1}$ corresponding to $v \mathrm{OH}$ and $v \mathrm{CN}$, respectively confirming the structure $6 \mathbf{a}$. Further confirmation of this structure was obtained from the ${ }^{1} \mathrm{H}-\mathrm{NMR}$ spectral analysis which showed, in addition to the phenyl protons, two characteristic signals assigned to $\mathrm{CH}_{3}$ and $\mathrm{OH}$ protons at 2.51 and $8.43 \mathrm{ppm}$, respectively. Alternatively, compound 6a was obtained through unequivocal synthesis via diazotization of the amino group of the derivative 7 [13], followed by decomposition of the resulting diazonium salt. The alkaline hydrolysis of 6a gave the hydroxycarboxylic acid 8 , which was esterified in refluxing absolute ethanol in the presence of concentrated $\mathrm{H}_{2} \mathrm{SO}_{4}$ to give the corresponding hydroxyester 9 . Contrary to the work of Rangnekar et al. [22], all attempts to prepare the latter compound $\mathbf{9}$ directly through the reaction of $\mathbf{1}$ with diethylmalonate under various conditions were unsuccessful (Scheme 2).

On the other hand, the interaction of $\mathbf{1}$ with $\alpha$-haloketones such as chloroacetone and phenacyl bromide gave the corresponding imidazo[4,5-c]pyrazole derivative $\mathbf{1 0}$ and $\mathbf{1 1}$ respectively. When the aminonitrosopyrazole 1 was reacted with thiobarbituric acid in refluxing pyridine, the reaction product was identified as 3-methyl-1-phenyl-7-thioxo-7,8-dihydro- $1 H$-pyrazolo[4,3-g]pteridin-5(6H)-one (12). Alkylation of 12 with excess ethyl iodide in DMF in the presence of anhydrous $\mathrm{K}_{2} \mathrm{CO}_{3}$ yielded 6-ethyl-7-(ethylthio)-3-methyl-1-phenyl-1H-pyrazolo[4,3-g]pteridin-5(6H)-one (13), however when $\mathbf{1 2}$ was interacted with one mole of ethyl chloroacetate, the ethyl mercaptoacetate derivative $\mathbf{1 4}$ was obtained (Scheme 3). 


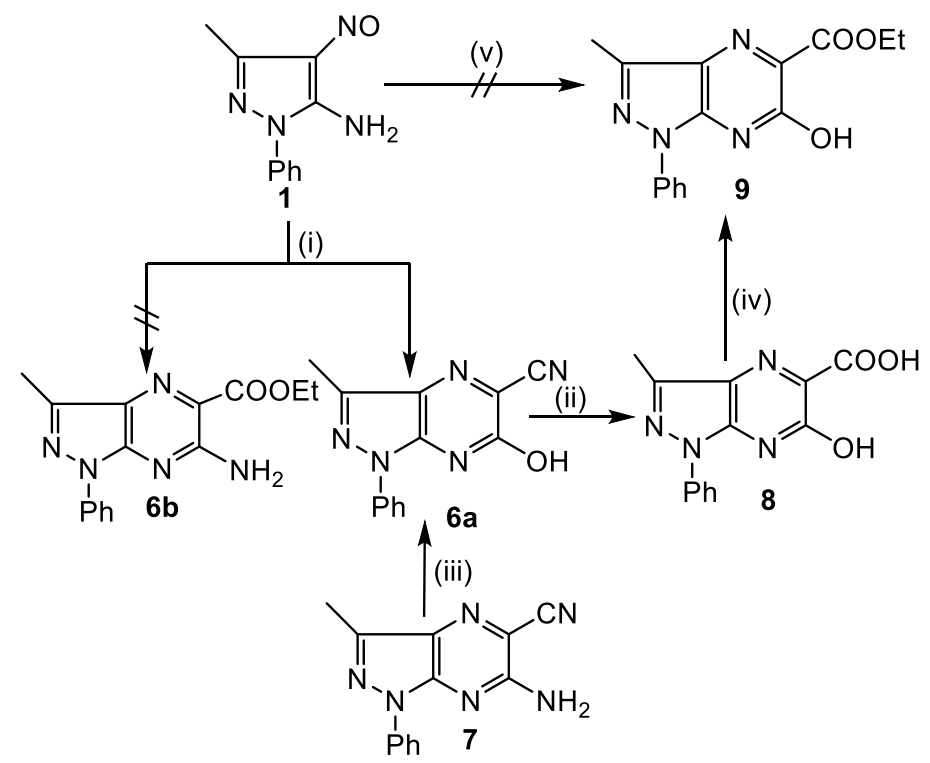

Scheme 2. Synthesis of compounds 6-9. Reagents and conditions: (i) $\mathrm{CH}_{2}(\mathrm{CN})\left(\mathrm{COOC}_{2} \mathrm{H}_{5}\right)$, pyridine, reflux overnight; (ii) $\mathrm{NaNO}_{2}, \mathrm{H}_{2} \mathrm{SO}_{4}$, room temperature (rt) at $0{ }^{\circ} \mathrm{C}$; (iii) $\mathrm{NaOH} 20 \%$, reflux 5 h; (iv) $\mathrm{EtOH}, \mathrm{HCl}$, reflux $6 \mathrm{~h}$; and (v) $\mathrm{CH}_{2}\left(\mathrm{COOC}_{2} \mathrm{H}_{5}\right)_{2}$, pyridine, reflux overnight.

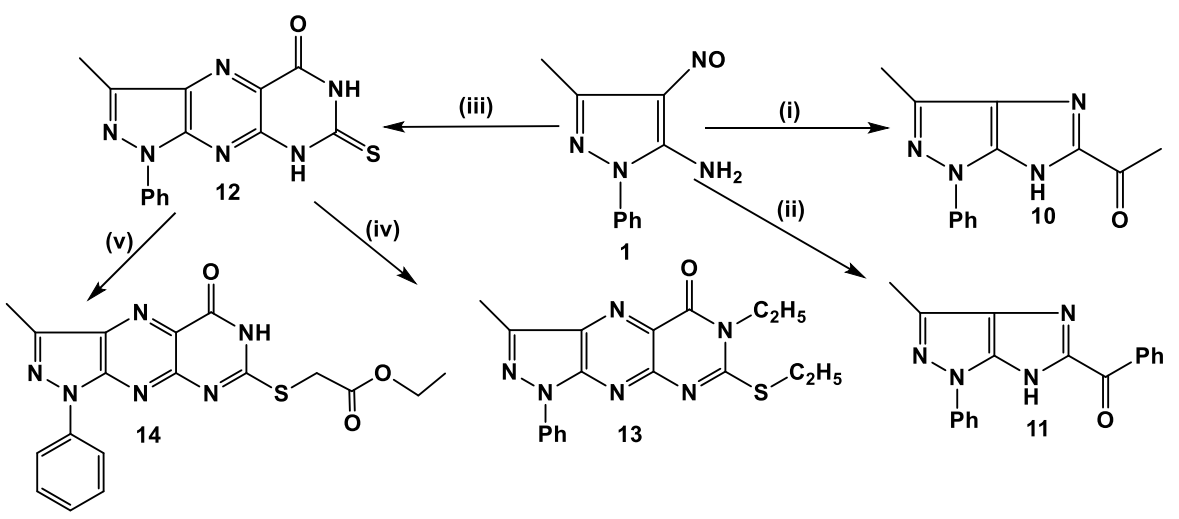

Scheme 3. Synthesis of compounds 10-14. Reagents and conditions: (i) $\mathrm{CH}_{3} \mathrm{COCH}_{2} \mathrm{Cl}$, pyridine, reflux overnight; (ii) $\mathrm{PhCOCH}_{2} \mathrm{Br}$, pyridine, reflux overnight; (iii) thiobarbituric acid, pyridine, reflux overnight; (iv) $\mathrm{C}_{2} \mathrm{H}_{5} \mathrm{I}, \mathrm{DMF}$, rt $5 \mathrm{~h}$; and (v) $\mathrm{ClCH}_{2} \mathrm{COOC}_{2} \mathrm{H}_{5}, \mathrm{DMF}$, rt $5 \mathrm{~h}$.

The interaction of $\mathbf{1}$ with acetylacetone under the same reaction conditions, the expected product 5-acetyl-3,6-dimethyl-1-phenyl-1H-pyrazolo[3,4-b]pyrazine (15) was obtained (Scheme 4).

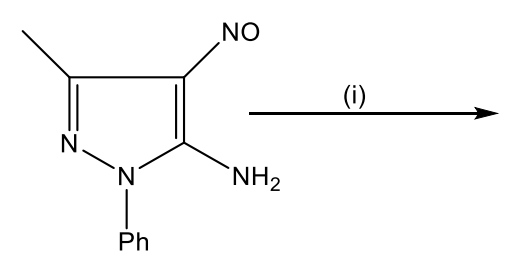<smiles>CC(=O)c1nc2c(C)nn(-c3ccccc3)c2nc1C</smiles>

15

Scheme 4. Synthesis of compound 15. Reagents and conditions: (i) $\mathrm{CH}_{2}\left(\mathrm{COCH}_{3}\right)_{2}$, dry pyridine, reflux $8 \mathrm{~h}$.

The acetyl derivative 15 was shown to be a useful key intermediate for the synthesis of several derivatives of the title compounds. Thus, the condensation of $\mathbf{1 5}$ with semicarbazide and thiosemicarbazide in boiling ethanol afforded the corresponding semicarbazone and 
thiosemicarbazone 16 and 17, respectively. On the other hand, when the acetyl function of $\mathbf{1 5}$ was interacted with hydroxyl amine the reaction product was identified as the oxime 18 . The hydrazone 19 was obtained via the interaction of $\mathbf{1 5}$ with hydrazine hydrate. Crossed aldol condensation between 5-acetylpyrazolo[3,4- $b$ ]pyrazine $\mathbf{1 5}$ and isatin was carried out in the presence of diethyl amine as a basic catalyst to give the 3-hydroxy-3-(2-(3,6-dimethyl-1-phenyl-1H-pyrazolo[3,4- $b$ ] pyrazine-5-yl)-2-oxoethyl)indolin-2-one (20). Dehydration of 20 by heating its ethanolic solution under reflux in the presence of concentrated $\mathrm{HCl}$ afforded the corresponding chalcone 21 (Scheme 5).

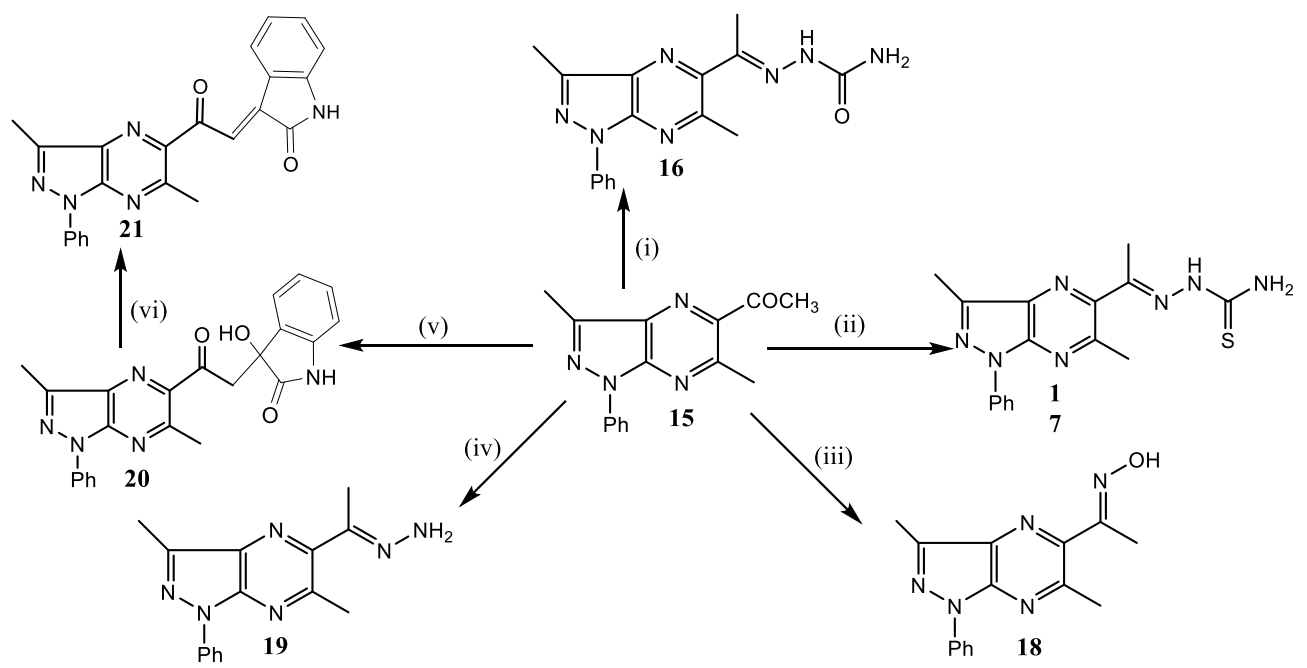

Scheme 5. Synthesis of compound 16-21. Reagents and conditions: (i) $\mathrm{NH}_{2} \mathrm{NHCONH}_{2} \cdot \mathrm{HCl}, \mathrm{EtOH}$, reflux $8 \mathrm{~h}$; (ii) $\mathrm{NH}_{2} \mathrm{NHCSNH}_{2}, \mathrm{EtOH}$, reflux $8 \mathrm{~h}$; (iii) $\mathrm{NH}_{2} \mathrm{OH} \cdot \mathrm{HCl}$, sodium acetate, EtOH, reflux 3-4 h; (iv) $\mathrm{NH}_{2} \mathrm{NH}_{2}$, reflux $6 \mathrm{~h}$; (v) isatin, $\left(\mathrm{C}_{2} \mathrm{H}_{5}\right)_{2} \mathrm{NH}$, EtOH, reflux overnight; and (v) $\mathrm{EtOH}, \mathrm{HCl}$, reflux $15 \mathrm{~min}$.

When the thiosemicarbazone $\mathbf{1 7}$ was allowed to react with $\alpha$-haloketones, such as chloroacetone and phenacyl bromide, the corresponding thiazolines 22,23 were obtained, while its reaction with $\alpha$-chloroacetic acid gave the thiazolidinone 24 (Scheme 6).

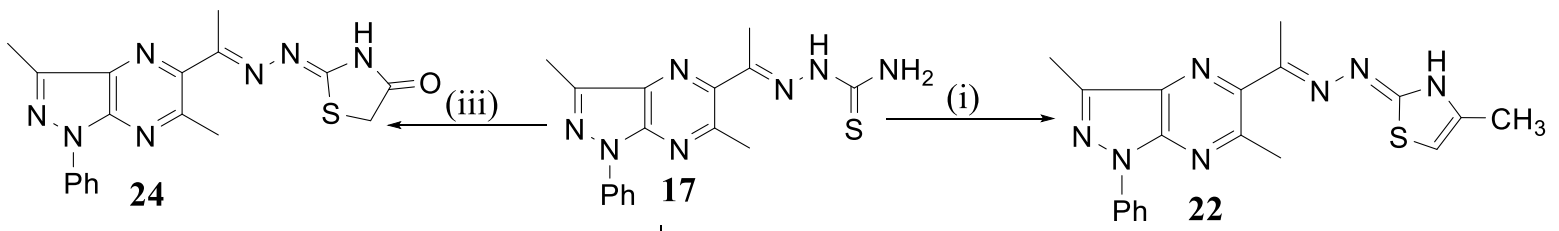<smiles>CC(=NN=c1[nH]c(-c2ccccc2)cs1)c1nc2c(C)nn(-c3ccccc3)c2nc1C</smiles>

Scheme 6. Synthesis of compound 22-24. Reagents and conditions: (i) $\mathrm{ClCH}_{2} \mathrm{COCH}_{3}$, anhyd. $\mathrm{CH}_{3} \mathrm{COONa}$, EtOH reflux 5 h; (ii) $\mathrm{PhCOCH}_{2} \mathrm{Br}$, anhyd. $\mathrm{CH}_{3} \mathrm{COONa}$, $\mathrm{EtOH}$, reflux $5 \mathrm{~h}$; and (iii) $\mathrm{ClCH}_{2} \mathrm{COOH}$, anhyd. $\mathrm{CH}_{3} \mathrm{COONa}$, EtOH, reflux $5 \mathrm{~h}$.

Chalcones are known by their biological activities and in particular by their anticancer activities [23-29]. Accordingly, a series of chalcones $\mathbf{2 5 a}-\mathbf{k}$ was synthesized via the Claisen-Schmidt reaction of $\mathbf{1 5}$ with a number of aromatic aldehydes (Scheme 7) for the sake of their evaluation against MCF-7 breast cancer cells. 
<smiles>CC#Cc1nc2c(nc1C(C)=O)c(C)nn2-c1ccccc1</smiles>

Scheme 7. Synthesis of chalcones 25a-k. Reagents and conditions: (i) $\mathrm{ArCHO}, \mathrm{EtOH}, 25 \%$ aq. $\mathrm{NaOH}$, rt overnight. $\mathbf{a}, \mathrm{Ar}=\mathrm{C}_{6} \mathrm{H}_{5} ; \mathbf{b}, \mathrm{Ar}=2-\mathrm{OHC}_{6} \mathrm{H}_{4} ; \mathbf{c}, \mathrm{Ar}=2-\mathrm{NO}_{2} \mathrm{C}_{6} \mathrm{H}_{4} ; \mathbf{d}, \mathrm{Ar}=4-\mathrm{NO}_{2} \mathrm{C}_{6} \mathrm{H}_{4} ; \mathbf{e}$, $\mathrm{Ar}=3-\mathrm{NO}_{2} \mathrm{C}_{6} \mathrm{H}_{4} ; \mathbf{f}, \mathrm{Ar}=4-\mathrm{CNC}_{6} \mathrm{H}_{4} ; \mathbf{g}, \mathrm{Ar}=4\left(\mathrm{CH}_{3} \mathrm{O}\right) \mathrm{C}_{6} \mathrm{H}_{4} ; \mathbf{h}, \mathrm{Ar}=4-\mathrm{N}_{(}\left(\mathrm{CH}_{3}\right)_{2} \mathrm{C}_{6} \mathrm{H}_{4} ; \mathbf{i}, \mathrm{Ar}=4-\mathrm{ClC}_{6} \mathrm{H}_{4}$; $\mathbf{j}, \mathrm{Ar}=3,4-\left(\mathrm{CH}_{3} \mathrm{O}\right)_{2} \mathrm{C}_{6} \mathrm{H}_{3}$; and $\mathbf{k}, \mathrm{Ar}=\mathrm{CH}=\mathrm{CH}-\mathrm{C}_{6} \mathrm{H}_{4}$.

On the other hand, the $\alpha, \beta$-unsaturated ketonic function of chalcones renders them ready to undergo reaction with bidentate nucleophiles to give five- and six-membered heterocyclic rings. Thus, the reaction of 25a with hydrazine hydrate and phenyl hydrazine in ethanol gave the corresponding pyrazolinyl derivatives 26 and 27, respectively. Also, the reaction of 25a with hydroxylamine hydrochloride in the presence of anhydrous sodium acetate led to the formation of the dihydroisoxazole 28. Moreover, the interaction of $\mathbf{2 5 a}$ with thiosemicarbazide in an ethanolic sodium hydroxide solution (25\%) yielded the pyrazolylthioamide 29. Finally, the treatment of 25 a with guanidine sulfate in ethanolic potassium hydroxide solution (10\%) yielded the 2-aminopyrimidine 30 (Scheme 8 ).

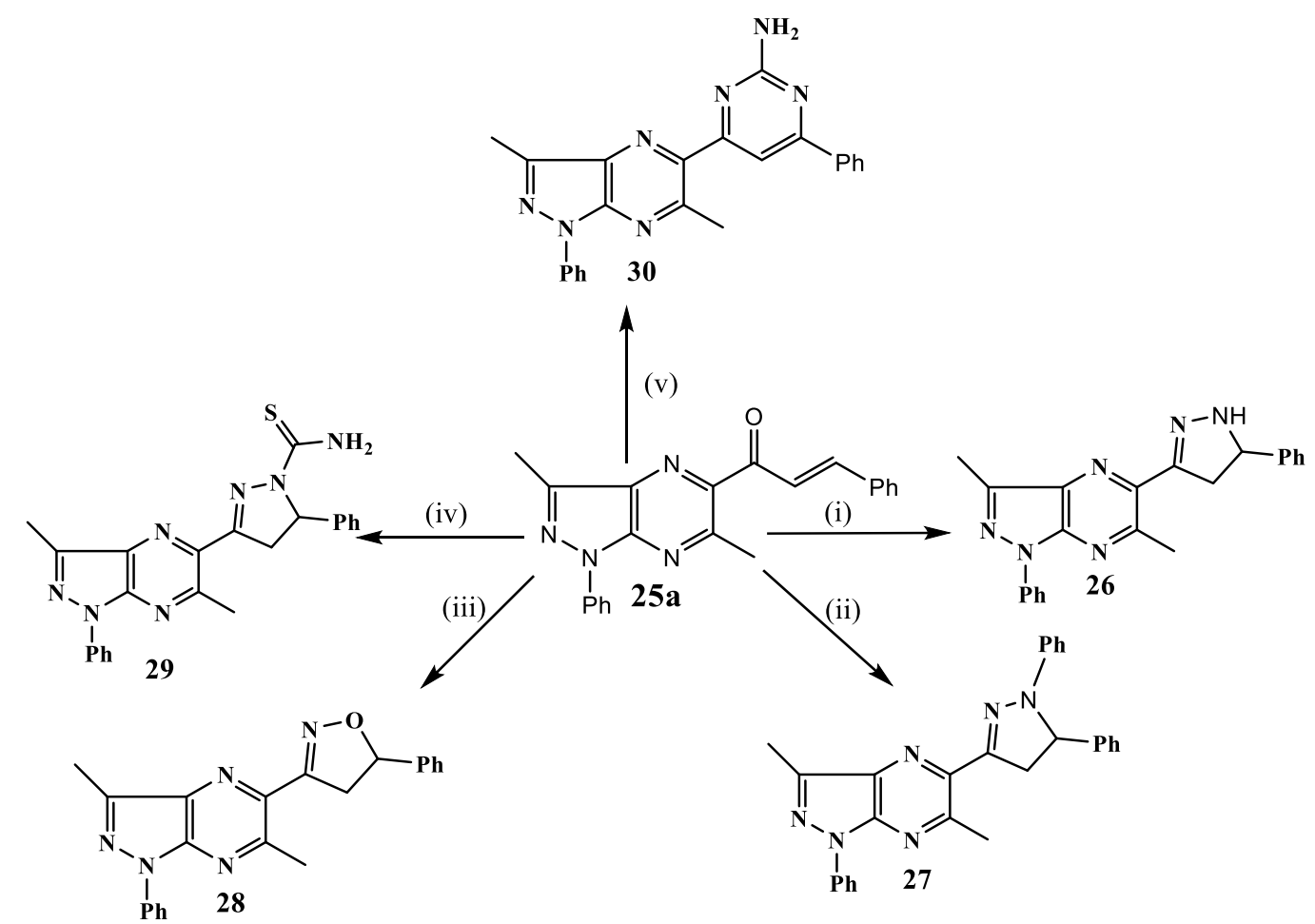

Scheme 8. Synthesis of compounds 26-30. Reagents and conditions: (i) $\mathrm{NHNH}_{2} \cdot \mathrm{H}_{2} \mathrm{O}, \mathrm{EtOH}$, reflux 10 h; (ii) $\mathrm{PhNHNH}_{2}$, EtOH, reflux 15 min; (iii) $\mathrm{NH}_{2} \mathrm{OH} \cdot \mathrm{HCl}, \mathrm{CH}_{3} \mathrm{COONa}, \mathrm{EtOH}$, reflux 6 h; (iv) $\mathrm{NH}_{2} \mathrm{NHCSNH}_{2}$, ethanolic $\mathrm{NaOH}(25 \%)$, reflux $3 \mathrm{~h}$; and (v) $\mathrm{NH}_{2} \mathrm{C}=\mathrm{NHNH}_{2} \cdot \mathrm{H}_{2} \mathrm{SO}_{4}$, ethanolic $\mathrm{KOH}(25 \%)$, reflux $3-4 \mathrm{~h}$.

\subsection{Biology}

\subsubsection{Anti-Inflammatory Activity}

Anti-inflammatory activity of compounds (15, 25a, 26-30) was evaluated against the carrageenan-induced rat oedema using indomethacin as the reference drug [30]. Mean changes 
in paw oedema thickness of the animals pretreated with the tested compounds after $0.5,1,2,3,4$, and $5 \mathrm{~h}$ from induction of inflammation was measured, and the inhibition percent of oedema by the tested compounds was calculated. The relative potencies \% of the tested compounds compared with indomethacin at the fifth hour was also calculated (Table 1). Amongst all the tested pyrazolopyrazines, the starting compound 5-acetyl-3,6-dimethyl-1-phenyl-1H-pyrazolo[3,4- $b$ ] pyrazine (15) showed the highest anti-inflammatory activity, compared to that of indomethacin $(44.44 \%)$. This activity was decreased when the acetyl derivative 15 was converted into its corresponding chalcone 25a, displaying $12.5 \%$ inhibition. An increase of this latter activity was shown by compounds 26 and 27, having pyrazolinyl substituent at 5-position of the pyrazolopyrazine nucleus (23.6\%, 15.07\% respectively). Substituting the 5-pyrazolinyl moiety by aminopyrimidinyl ring (compound 30) results in more increase in activity (27\%). Higher activity (34\%) was observed when the latter aminopyrimidinyl ring was replaced by isoxazolinyl moiety (compound 28). Noticeable increase of potency (close to that of indomethacin) was shown by the pyrazolylthioamide derivative 29 (40\%).

Table 1. Anti-inflammatory Activity of Tested Compounds (15, 25a, 26-30) against Acute Carrageenan-Induced Paw Oedema in Rats (Statistical analysis).

\begin{tabular}{|c|c|c|c|c|c|c|c|}
\hline \multirow{2}{*}{ Compound ${ }^{a}$} & \multicolumn{7}{|c|}{ Paw Oedema Inhibition (Swell \pm S.E.M.) ${ }^{a, b, c}(\%)$} \\
\hline & $30 \mathrm{~min}$ & 1 (h) & 2 (h) & 3 (h) & 4 (h) & 5 (h) & Potency $^{d}$ \\
\hline & \multicolumn{7}{|c|}{ Edema Induced by Carrageenan (\% Edema Inhibition Relative to Control) } \\
\hline 15 & $0.40 \pm 0.00$ & $0.55 \pm 0.03$ & $0.48 \pm 0.02$ & $0.42 \pm 0.02$ & $0.38 \pm 0.02$ & $0.40 \pm 0.00$ & 44.44 \\
\hline $25 a$ & $0.63 \pm 0.03$ & $0.66 \pm 0.03$ & $0.65 \pm 0.03$ & $0.66 \pm 0.02$ & $0.63 \pm 0.02$ & $0.63 \pm 0.03$ & 12.50 \\
\hline 26 & $0.55 \pm 0.03$ & $0.68 \pm 0.02$ & $0.66 \pm 0.02$ & $0.62 \pm 0.02$ & $0.62 \pm 0.02$ & $0.55 \pm 0.03$ & 23.61 \\
\hline 27 & $0.61 \pm 0.02$ & $0.68 \pm 0.02$ & $0.60 \pm 0.03$ & $0.60 \pm 0.03$ & $0.63 \pm 0.02$ & $0.62 \pm 0.02$ & 15.07 \\
\hline 28 & $0.46 \pm 0.02$ & $0.63 \pm 0.02$ & $0.63 \pm 0.02$ & $0.60 \pm 0.03$ & $0.48 \pm 0.02$ & $0.47 \pm 0.02$ & 34.72 \\
\hline 29 & $0.43 \pm 0.00$ & $0.45 \pm 0.03$ & $0.43 \pm 0.02$ & $0.42 \pm 0.02$ & $0.38 \pm 0.03$ & $0.43 \pm 0.02$ & 40.27 \\
\hline 30 & $0.51 \pm 0.02$ & $0.61 \pm 0.02$ & $0.55 \pm 0.05$ & $0.45 \pm 0.03$ & $0.45 \pm 0.03$ & $0.52 \pm 0.02$ & 27.77 \\
\hline Drug * & $0.40 \pm 0.00$ & $0.45 \pm 0.03$ & $0.42 \pm 0.02$ & $0.38 \pm 0.0$ & $0.37 \pm 0.02$ & $0.40 \pm 0.00$ & 44.44 \\
\hline Negative Control & $0.72 \pm 0.02$ & $0.73 \pm 0.02$ & $0.73 \pm 0.02$ & $0.72 \pm 0.02$ & $0.73 \pm 0.02$ & $0.72 \pm 0.02$ & - \\
\hline
\end{tabular}

$\left({ }^{\mathrm{a}}\right)$ Dose $28 \mu \mathrm{M} / \mathrm{kg} .\left({ }^{\mathrm{b}}\right) n=6 .\left({ }^{\mathrm{c}}\right)$ Statistically significant from the indomethacin at $p<0.05$. $\left({ }^{\mathrm{d}}\right)$ Potency was expressed as $\%$ oedema inhibition of the tested compounds relative to $\%$ oedema inhibition of indomethacin (reference drug).

* Drug $=$ indomethacin $(28 \mu \mathrm{M} / \mathrm{kg})$.

The percent oedema inhibition was calculated from the mean effect shown by the control and treated animals according to the following equation:

$$
\text { Percent oedema inhibition }=\frac{\mathrm{v}_{\mathrm{c}}-\mathrm{v}_{\mathrm{t}}}{\mathrm{v}_{\mathrm{c}}} \times 100
$$

where $v_{C}$ represents the mean increase in paw volume in the control group of rats and $v_{t}$ represents the mean increase in paw volume in rats treated with tested compounds. The potency was calculated as the percentage of the change of the standard and tested compounds, as depicted in Table 1. All the results are expressed as the mean \pm standard error of the mean (S.E.M.). Statistical evaluations were performed using graph pad prism program software version 5.00 through One-way ANOVA.

\subsubsection{Cytotoxic Activity}

The chalcones 25a-k along with their starting compound 15 were evaluated for their cytotoxic activity against MCF-7 breast cancer cells using 3-(4,5-dimethylthiazol-2yl)-2,5-diphenyl tetrazolium bromide (MTT) cell viability assay according to literature procedure [31]. The results obtained revealed that the parent acetyl compound 15 exhibited an inhibitory activity with $\mathrm{IC}_{50}$ value of $9.42 \mu \mathrm{M}$ (Figure 1). The chalcone 25a, with unsubstituted phenyl group in the $\alpha, \beta$-unsaturated ketonic function, showed higher activity than that of the parent compound 15. An increase in activity was observed upon replacement of this phenyl ring by a phenyl ethen-2-yl group (25k). The effect of substitution in the phenyl group of 25a on the cytotoxic activity was studied. Thus, the introduction of an $\mathrm{OH}$ 
group in the 2-position of this phenyl group (25b) led to an improvement of the activity. On the other hand, the introduction of an $\mathrm{NO}_{2}$ group showed variable activities according to its position, where the activity was in the order 4- > 2- > 3-nitro isomer (25d, 25c, 25e). Replacement of the 4- $\mathrm{NO}_{2}$ group by a $\mathrm{CN}$ or $\mathrm{OCH}_{3}$ function (25f and $\mathbf{2 5 g}$ ) lowered the cytotoxic activity. However, its replacement by 4-N,N-dimethylamino group (25h) resulted in higher cytotoxic activity than all the former derivatives with $\mathrm{IC}_{50}$ of $3.66 \mu \mathrm{M}$. A further higher activity was shown by the 4-Cl derivative (25i), while the highest activity was shown by the 3,4-dimethoxy derivative (25j) with $\mathrm{IC}_{50}$ value of $2.22 \mu \mathrm{M}$. The reference drug Paclitaxel showed an $\mathrm{IC}_{50}$ of $1.02 \mu \mathrm{M}$ (Figure 2$)$.

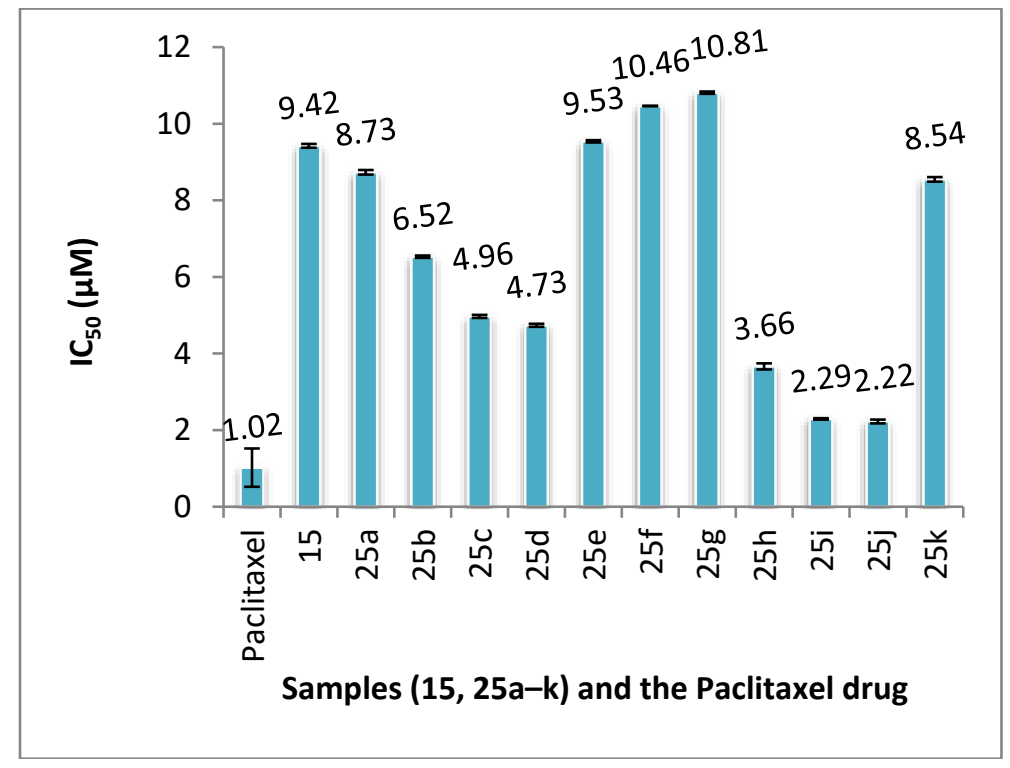

Figure 1. Effect of compounds $(\mathbf{1 5}, \mathbf{2 5 a}-\mathbf{k})$ on the proliferation of MCF-7 breast cancer cells using 3-(4,5-dimethylthiazol-2yl)-2,5-diphenyl tetrazolium bromide (MTT) cell viability assay. The $\mathrm{IC}_{50}$ of the tested compounds was calculated after $24 \mathrm{~h}$.

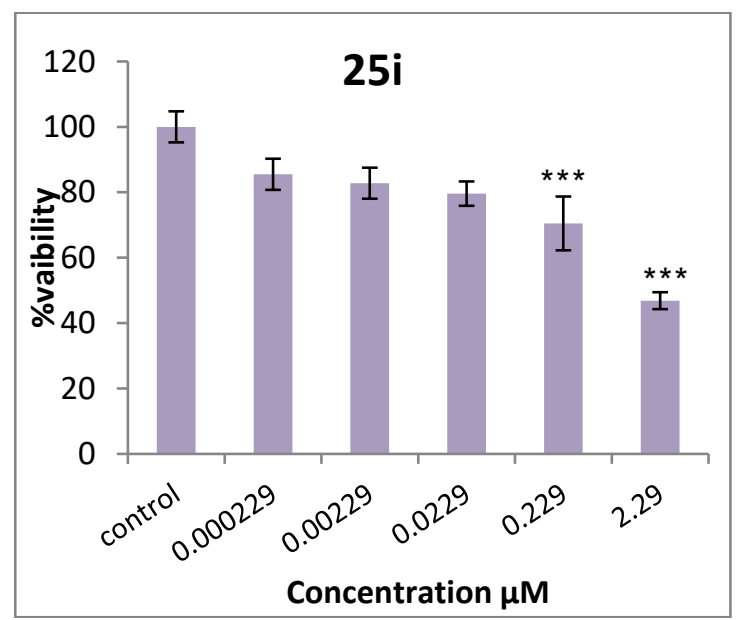

Figure 2. Cytotoxic effect of compounds 25i, 25j against the proliferation of MCF-7 breast cancer cells. Cells were treated with the indicated doses and cell viability was obtained using MTT cell viability assay. ${ }^{* * *} p<0.001$ calculated by comparing each concentration with the control. The data were normally distributed and were expressed as the mean \pm standard error of the mean (SEM). Two-tailed paired student test $p$-values as determined by Graphpad Prism software is indicated as ${ }^{* * *} p<0.001$. 


\section{Experimental}

\subsection{Chemistry}

All melting points were determined on a Stuart melting point apparatus SMP3 (Sigma-Aldrich, Saint Louise, MI, USA). IR spectra were recorded on a Nicolet iS10 FT-IR spectrometer (Thermo Fisher, Waltham, MA, USA) using $\mathrm{KBr}$ wafer technique. The ${ }^{1} \mathrm{H}-\mathrm{NMR}$ spectra were recorded on Bruker AV500 (400 MHz) (Bruker, Billerica, MA, USA) and Bruker Avance III (400 MHz) spectrometers (Bruker). ${ }^{1} \mathrm{H}$ - and ${ }^{13} \mathrm{C}-\mathrm{NMR}$ chemical shifts $\delta$ were reported in parts per million (ppm) and were referenced to the solvent peak; $\mathrm{CDCl}_{3}\left(7.26 \mathrm{ppm}\right.$ for ${ }^{1} \mathrm{H}$ and $76.90 \mathrm{ppm}$ for $\left.{ }^{13} \mathrm{C}\right)$ and DMSO- $d_{6}\left(2.50 \mathrm{ppm}\right.$ for ${ }^{1} \mathrm{H}$ and $39.70 \mathrm{ppm}$ for ${ }^{13} \mathrm{C}$ ). Multiplicities are represented by s (singlet), $\mathrm{d}$ (doublet), $\mathrm{t}$ (triplet), q (quartet), and $\mathrm{m}$ (multiplet). Coupling constants $(J)$ are reported in Hertz $(\mathrm{Hz})$. Mass spectra were taken on a Jeol JMS-600 mass spectrometer (Jeol Inc., Peabody, MA, USA). Elemental analyses were carried out using a Perkin Elmer $240 \mathrm{C}$ Micro analyzer (Perkin Elmer, Waltham, MA, USA) and they were found to be within $\pm 0.4 \%$ of the theoretical values. Their results were found in good agreement with the calculated values. Paclitaxel and 3-(4,5-dimethylthiazol-2yl)-2,5-diphenyl tetrazolium bromide (MTT) were purchased from Sigma Aldrich, more detailed IR and NMR data can be found in the Supplementary Materials.

6-Hydroxy-3-methyl-1-phenyl-1H-pyrazolo[3,4-b]pyrazine-5-carbonitrile (6a). Procedure (1): A mixture of compound $1(3.0 \mathrm{~g}, 1.5 \mathrm{mmol})$ and ethyl cyanoacetate $(1.8 \mathrm{~mL}, 1.5 \mathrm{mmol})$ in dry pyridine $(20 \mathrm{~mL})$ was heated under reflux for overnight. After cooling, the solid product obtained was filtered, washed with water, and dried. Recrystallization from ethanol-water mixture (2:1) gave fine yellow needles, yield $0.68 \mathrm{~g}(68 \%)$, m.p. $240-242{ }^{\circ} \mathrm{C}$. Procedure (2): Compound 7 [13] (0.5 g, $\left.2 \mathrm{mmol}\right)$ was dissolved in cold $\mathrm{H}_{2} \mathrm{SO}_{4}(5 \mathrm{~mL})$, then a cold sodium nitrite solution $\left(0.4 \mathrm{~g}\right.$ in $\left.2 \mathrm{~mL} \mathrm{H}_{2} \mathrm{O}\right)$ was added dropwise under stirring to the above solution during $0.5 \mathrm{~h}$ in an ice bath at $0-5^{\circ} \mathrm{C}$. The reaction mixture was allowed to stir at room temperature (rt) for $1 \mathrm{~h}$ further, then it was poured onto ice-water mixture. The solid product obtained was filtered, washed with water, and recrystallized from ethanol-water mixture (2:1) as yellow crystals, yield $0.3 \mathrm{~g}(60 \%), \mathrm{m} . \mathrm{p} .240-242{ }^{\circ} \mathrm{C}$. IR $\left(v, \mathrm{~cm}^{-1}\right): 3197(\mathrm{OH}), 3073(\mathrm{CH}$ aromatic), $2234(\mathrm{C} \equiv \mathrm{N}) .{ }^{1} \mathrm{H}-\mathrm{NMR}\left(400 \mathrm{MHz}, \mathrm{DMSO}-d_{6}\right) \delta(\mathrm{ppm}): 2.51\left(\mathrm{~s}, 3 \mathrm{H}, \mathrm{CH}_{3}\right), 7.38(\mathrm{t}, 1 \mathrm{H}$, phenyl), $7.57(\mathrm{t}, 2 \mathrm{H}$, phenyl), 8.08 (d, 2H, phenyl), $8.43(\mathrm{~s}, 1 \mathrm{H}, \mathrm{OH}) .{ }^{13} \mathrm{C}-\mathrm{NMR}\left(100 \mathrm{MHz}, \mathrm{DMSO}-d_{6}\right) \delta(\mathrm{ppm}): 10.99\left(\mathrm{CH}_{3}\right)$, $114.58(\mathrm{C}), 115.73(\mathrm{C} \equiv \mathrm{N}), 120.28(2 \mathrm{CH}), 126.55(\mathrm{CH}), 129.01(\mathrm{C}), 129.31(2 \mathrm{CH}), 137.89(\mathrm{C}), 141.84(\mathrm{C})$, 144.48 (C), 160.40 (C) MS: $m / z\left(251 \mathrm{M}^{+}\right)$. Anal. calcd. for $\mathrm{C}_{13} \mathrm{H}_{9} \mathrm{~N}_{5} \mathrm{O}$ (251.24): C, 62.15; $\mathrm{H}, 3.61 ; \mathrm{N}, 27.87$. Found: $\mathrm{C}, 62.30 ; \mathrm{H}, 3.50 ; \mathrm{N}, 27.72 \%$.

6-Hydroxy-3-methyl-1-phenyl-1H-pyrazolo[3,4-b]pyrazine-5-carboxylic acid (8): The hydroxy cyano compound $6 \mathbf{a}(0.5 \mathrm{~g})$ was dissolved in $\mathrm{EtOH}(10 \mathrm{~mL})$, then aqueous solution of $\mathrm{NaOH}(20 \%, 10 \mathrm{~mL})$ was added. The reaction mixture was heated under reflux for $5 \mathrm{~h}$, then it was evaporated to half of its volume. After cooling, it was neutralized with dil. $\mathrm{HCl}$, giving a solid precipitate which was filtered off, washed with water, dried, and recrystallized from dioxane as yellow crystals, yield $0.4 \mathrm{~g}(80 \%)$, m.p. 190-192 ${ }^{\circ} \mathrm{C}$. IR $\left(v, \mathrm{~cm}^{-1}\right)$ : $3493(\mathrm{OH}), 2969,2920,2862$ (CH aliph.), 3350-2493 (characteristic of $\mathrm{COOH}), 1667(\mathrm{C}=\mathrm{O}) .{ }^{1} \mathrm{H}-\mathrm{NMR}\left(400 \mathrm{MHz}, \mathrm{DMSO}-d_{6}\right) \delta(\mathrm{ppm}): 2.57\left(\mathrm{~s}, 3 \mathrm{H}, \mathrm{CH}_{3}\right), 7.33(\mathrm{t}, 1 \mathrm{H}$, phenyl), $7.55\left(\mathrm{t}, 2 \mathrm{H}\right.$, phenyl), $8.12\left(\mathrm{~d}, 2 \mathrm{H}\right.$, phenyl), $8.38(\mathrm{~s}, 1 \mathrm{H}, \mathrm{OH}) .{ }^{13} \mathrm{C}-\mathrm{NMR}\left(100 \mathrm{MHz}, \mathrm{DMSO}-d_{6}\right): 11.76\left(\mathrm{CH}_{3}\right)$, $119.67(2 \mathrm{CH}, \mathrm{C}), 125.59$ ( $\mathrm{CH}, \mathrm{C}), 129.53(2 \mathrm{CH}, \mathrm{C}), 139.55$ (2C), 144.77 (C), 165.16 (C). Anal. calcd. for $\mathrm{C}_{13} \mathrm{H}_{10} \mathrm{~N}_{4} \mathrm{O}_{3}$ (270.24): C, 57.78; H, 3.73; N, 20.73. Found. C, 57.66; H, 3.88; N, 20.56\%.

Ethyl 6-hydroxy-3-methyl-1-phenyl-1H-pyrazolo[3,4-b]pyrazine-5-carboxylate (9): To the hydroxy acid 8 $(0.5 \mathrm{~g}, 1 \mathrm{mmol})$ in anhydrous ethanol $(20 \mathrm{~mL})$, conc. $\mathrm{HCl}(15 \mathrm{~mL})$ was added, and the mixture was heated under reflux for $6 \mathrm{~h}$. The reaction mixture was then cooled, poured on ice-cold solution of $\mathrm{NaHCO}_{3}$, and the solid precipitate was filtered, washed with water, and dried. Crystallization from dioxane-water mixture (2:1) gave pale brown crystals, yield $0.35 \mathrm{~g}(70 \%), \mathrm{m} . p .143-145^{\circ} \mathrm{C}$. IR $\left(\mathrm{v}, \mathrm{cm}^{-1}\right)$ : $3117(\mathrm{OH}), 2974$ (CH aliph.), 1677 (C=O). ${ }^{1} \mathrm{H}-\mathrm{NMR}\left(400 \mathrm{MHz}, \mathrm{CDCl}_{3}\right) \delta(\mathrm{ppm}): 1.57$ (t, $J=7.1 \mathrm{~Hz}, 3 \mathrm{H}$, $\left.\mathrm{CH}_{3}\right), 2.76\left(\mathrm{~s}, 3 \mathrm{H}, \mathrm{CH}_{3}\right), 4.64\left(\mathrm{q}, J=7.1 \mathrm{~Hz}, 2 \mathrm{H}, \mathrm{CH}_{2}\right), 7.33(\mathrm{t}, 1 \mathrm{H}$, phenyl), $7.53(\mathrm{t}, 2 \mathrm{H}$, phenyl), $8.25(\mathrm{~d}$, 
2H, phenyl), $12.08(\mathrm{~s}, 1 \mathrm{H}, \mathrm{OH}),{ }^{13} \mathrm{C}-\mathrm{NMR}\left(100 \mathrm{MHz}, \mathrm{CDCl}_{3}\right): 11.64\left(\mathrm{CH}_{3}\right), 14.20\left(\mathrm{CH}_{3}\right), 63.48\left(\mathrm{CH}_{2}\right)$, $120.32(2 \mathrm{CH}), 123.05(\mathrm{C}) 126.37(\mathrm{CH}), 129.23(2 \mathrm{CH}), 130.58$ (C), 138.39 (C), 143.09 (C), $145.8(\mathrm{C})$, 161.27 (C), $169.07(\mathrm{C}=\mathrm{O})$. MS: $m / z\left(298 \mathrm{M}^{+}\right)$. Anal. calcd. for $\mathrm{C}_{15} \mathrm{H}_{14} \mathrm{~N}_{4} \mathrm{O}_{3}(298.30)$ : $\mathrm{C}, 60.40 ; \mathrm{H}, 4.73 ; \mathrm{N}$, 18.78. Found: $\mathrm{C}, 60.30 ; \mathrm{H}, 4.50 ; \mathrm{N}, 18.92 \%$.

5-Acetyl-3-methyl-1-phenyl-1H,6H-imidazo[4,5-c]pyrazole (10): A mixture of compound 1 (1.0 g, 5 mmol) and chloro acetone $(0.46 \mathrm{~mL}, 5 \mathrm{mmol})$ in dry pyridine $(15 \mathrm{~mL})$ was heated under reflux for overnight. After cooling the solid product was filtered, washed with water, and recrystallized from ethanol-dioxane mixture (2:1) as fine yellow needles, yield $0.52 \mathrm{~g}(98 \%), \mathrm{m} . \mathrm{p} .288-290^{\circ} \mathrm{C}$. IR $\left(v, \mathrm{~cm}^{-1}\right)$ : $3438(\mathrm{NH}), 2922,2784$ (CH aliph.), 1655 (C=O). ${ }^{1} \mathrm{H}-\mathrm{NMR}$ (400 MHz, DMSO-d 6 ) $\delta$ (ppm): $2.40(\mathrm{~s}, 3 \mathrm{H}$, $\left.\mathrm{CH}_{3}\right), 2.60\left(\mathrm{~s}, 3 \mathrm{H}, \mathrm{CH}_{3}\right), 7.33(\mathrm{t}, 1 \mathrm{H}$, phenyl), $7.52(\mathrm{t}, 2 \mathrm{H}$, phenyl), $7.6(\mathrm{~s}, 1 \mathrm{H}, \mathrm{NH}), 8.11(\mathrm{~d}, 2 \mathrm{H}$, phenyl). ${ }^{13} \mathrm{C}-\mathrm{NMR}\left(100 \mathrm{MHz}, \mathrm{DMSO}-d_{6}\right) \delta(\mathrm{ppm}): 11.26\left(\mathrm{CH}_{3}\right), 21.17\left(\mathrm{CH}_{3}\right), 119.87(2 \mathrm{CH}), 125.79(\mathrm{CH}, \mathrm{C})$, $129.19(2 \mathrm{CH}, \mathrm{C}), 138.82(2 \mathrm{C}), 155.33(\mathrm{C}=\mathrm{O})$. Anal. calcd. for $\mathrm{C}_{13} \mathrm{H}_{12} \mathrm{~N}_{4} \mathrm{O}(240.26): \mathrm{C}, 64.99 ; \mathrm{H}, 5.03 ; \mathrm{N}$, 23.32. Found: $\mathrm{C}, 64.60 ; \mathrm{H}, 5.21 ; \mathrm{N}, 23.40 \%$.

5-Benzoyl-3-methyl-1-phenyl-1H,6H-imidazo[4,5-c]pyrazole (11): A mixture of compound 1 (1.0 g, 5 mmol) and phenacyl bromide $(0.46 \mathrm{~g}, 5 \mathrm{mmol})$ in dry pyridine $(15 \mathrm{~mL})$ was heated under reflux for overnight. After cooling the solid product was filtered, washed with water, dried, and recrystallized from ethanol-dioxane mixture (1:1) as yellow needles, yield $0.8 \mathrm{~g}(88 \%), \mathrm{m} . \mathrm{p} .304-306^{\circ} \mathrm{C}$. IR $\left(v, \mathrm{~cm}^{-1}\right)$ : $3075(\mathrm{NH}), 2921,2781$ (CH aliph.), 1641 (C=O). ${ }^{1} \mathrm{H}-\mathrm{NMR}\left(400 \mathrm{MHz}, \mathrm{DMSO}-d_{6}\right) \delta(\mathrm{ppm}): 2.76(\mathrm{~s}, 3 \mathrm{H}$, $\left.\mathrm{CH}_{3}\right), 7.33(\mathrm{t}, 1 \mathrm{H}$, phenyl), $7.41(\mathrm{t}, 1 \mathrm{H}$, phenyl), 7.65-7.50 (m, 5H, phenyl), 8.12-8.31 (m, 3H, phenyl), $12.85(\mathrm{~s}, 1 \mathrm{H}, \mathrm{NH}) .{ }^{13} \mathrm{C}-\mathrm{NMR}\left(100 \mathrm{MHz}, \mathrm{DMSO}-d_{6}\right) \delta(\mathrm{ppm}): 14.08\left(\mathrm{CH}_{3}\right), 120.327(\mathrm{C}), 120.99(2 \mathrm{CH})$, $123.08(\mathrm{CH}), 126.78(\mathrm{CH}), 127.02(\mathrm{CH}), 127.96(\mathrm{CH}), 128.45(\mathrm{CH}), 129.57(\mathrm{CH}), 129.77(\mathrm{CH}), 129.88(\mathrm{CH})$, 131.49 (C), 135.14 (C), 139.11 (C), 154.56 (C), 155.46 (C), 177.73 (C). MS: $m / z\left(302 \mathrm{M}^{+}\right)$. Anal. calcd. for $\mathrm{C}_{18} \mathrm{H}_{14} \mathrm{~N}_{4} \mathrm{O}$ (302.33): C, 71.51; $\mathrm{H}, 4.67 ; \mathrm{N}, 18.53$. Found: $\mathrm{C}, 71.62 ; \mathrm{H}, 4.25 ; \mathrm{N}, 18.72 \%$.

3-Methyl-1-phenyl-7-thioxo-7,8-dihydro-1H-pyrazolo[4,3-g]pteridin-5(6H)-one (12): A mixture of amino nitroso $1(1.01 \mathrm{~g}, 5 \mathrm{mmol})$ and thiobarbituric acid $(0.72 \mathrm{~g}, 5 \mathrm{mmol})$ in dry pyridine $(20 \mathrm{~mL})$ was heated under reflux for overnight. After cooling, the solid product was filtered, washed with water, and recrystallized from ethanol-dioxane mixture (1:3) as fine yellow needles, yield $0.15 \mathrm{~g}(65 \%)$, m.p. $332-334{ }^{\circ} \mathrm{C}$. IR $\left(v, \mathrm{~cm}^{-1}\right)$ : $3416(\mathrm{NH}), 3068$ (CH arom.), 2891 ( $\mathrm{CH}$ aliph.), $1693(\mathrm{C}=\mathrm{O}) .{ }^{1} \mathrm{H}-\mathrm{NMR}$ $\left(400 \mathrm{MHz}, \mathrm{DMSO}-d_{6}\right), \delta(\mathrm{ppm}): 2.70\left(\mathrm{~s}, 1 \mathrm{H}, \mathrm{CH}_{3}\right), 7.27(\mathrm{t}, 1 \mathrm{H}$, phenyl), $7.45(\mathrm{t}, 2 \mathrm{H}$, phenyl), $8.13(\mathrm{~d}, 2 \mathrm{H}$, phenyl), 11.76 (s, 1H, NH), $11.91(\mathrm{~s}, 1 \mathrm{H}, \mathrm{NH}),{ }^{13} \mathrm{C}-\mathrm{NMR}$ (100 MHz, DMSO- $\left.d_{6}\right) \delta(\mathrm{ppm}): 11.29(\mathrm{~s}, 3 \mathrm{H}$, $\left.\mathrm{CH}_{3}\right), 119.60(2 \mathrm{CH}), 126.36(\mathrm{CH}), 126.99(\mathrm{C}), 129.37(2 \mathrm{CH}), 132.78(\mathrm{C}), 138.13(\mathrm{C}), 142.42(\mathrm{C}), 145.60(\mathrm{C})$, 147.27 (C), $158.31(\mathrm{C}=\mathrm{O}), 175.95(\mathrm{C}=\mathrm{S})$. MS: $\mathrm{m} / z\left(310 \mathrm{M}^{+}\right)$. Anal. calcd. for $\mathrm{C}_{14} \mathrm{H}_{10} \mathrm{~N}_{5} \mathrm{OS}$ (310.3): $\mathrm{C}$, 54.18; H, 3.25; N, 27.08 Found: C, 54.02; H, 3.21; N, 26.82\%.

6-Ethyl-7-(ethylthio)-3-methyl-1-phenyl-1H-pyrazolo[4,3-g]pteridin-5(6H)-one (13): A mixture of the thione $12(0.25 \mathrm{~g}, 0.8 \mathrm{mmol})$, ethyl iodide $(0.24 \mathrm{~g}, 1.6 \mathrm{mmol})$, and anhydrous $\mathrm{K}_{2} \mathrm{CO}_{3}(0.41 \mathrm{~g}, 3 \mathrm{mmol})$ in $\operatorname{DMF}(15 \mathrm{~mL})$ was stirred at $80^{\circ} \mathrm{C}$ for $5 \mathrm{~h}$. After cooling the solid product was filtered, washed with water, dried, and recrystallized from ethanol-acetone mixture (2:1) to give yellow crystals, yield $0.25 \mathrm{~g}$ (86\%), m.p. $238-240{ }^{\circ} \mathrm{C} . \mathrm{IR}\left(v, \mathrm{~cm}^{-1}\right)$ : 2922, 2784 (CH aliph.), 1655 (C=O). ${ }^{1} \mathrm{H}-\mathrm{NMR}\left(400 \mathrm{MHz}, \mathrm{CDCl}_{3}\right)$ $\delta(\mathrm{ppm}): 1.47\left(\mathrm{t}, J=7.1 \mathrm{~Hz}, 3 \mathrm{H}, \mathrm{CH}_{3}\right), 1.53\left(\mathrm{t}, J=7.4 \mathrm{~Hz}, 3 \mathrm{H}, \mathrm{CH}_{3}\right), 2.86\left(\mathrm{~s}, 3 \mathrm{H}, \mathrm{CH}_{3}\right), 3.51(\mathrm{q}, J=7.4 \mathrm{~Hz}$, $\left.2 \mathrm{H}, \mathrm{CH}_{2}\right), 4.34\left(\mathrm{q}, J=7.0 \mathrm{~Hz}, 2 \mathrm{H}, \mathrm{CH}_{2}\right), 7.35(\mathrm{t}, J=7.3 \mathrm{~Hz}, 1 \mathrm{H}$, phenyl), $7.57(\mathrm{t}, J=7.8 \mathrm{~Hz}, 2 \mathrm{H}$, phenyl), $8.33\left(\mathrm{~d}, J=8.4 \mathrm{~Hz}, 2 \mathrm{H}\right.$, phenyl). ${ }^{13} \mathrm{C}-\mathrm{NMR}\left(100 \mathrm{MHz}, \mathrm{CDCl}_{3}\right) \delta(\mathrm{ppm}): 11.75\left(\mathrm{CH}_{3}\right), 12.93\left(\mathrm{CH}_{3}\right)$, 13.68 $\left(\mathrm{CH}_{3}\right), 27.05\left(\mathrm{CH}_{2}\right), 40.44\left(\mathrm{CH}_{2}\right), 120.25(2 \mathrm{CH}), 125.89(\mathrm{CH}), 128.22(\mathrm{C}), 129.21(2 \mathrm{CH}), 135.53(\mathrm{C})$, 138.67 (C), 144.52 (C), 145.96 (C), 151.08 (C), 160.43 (C), 162.82 (C=O). MS: $m / z\left(366 \mathrm{M}^{+}\right)$. Anal. calcd. for $\mathrm{C}_{18} \mathrm{H}_{18} \mathrm{~N}_{6} \mathrm{OS}$ (366.44): $\mathrm{C}, 59.00 ; \mathrm{H}, 4.95 ; \mathrm{N}, 22.93$. Found: $\mathrm{C}, 59.25 ; \mathrm{H}, 4.72 ; \mathrm{N}, 22.65 \%$.

Ethyl 2-(3-methyl-5-oxo-1-phenyl-5,6-dihydro-1H-pyrazolo[4,3-g]pteridin-7-ylthio)acetate. (14): A mixture of the thione $12(0.15 \mathrm{~g}, 0.4 \mathrm{mmol})$, ethyl chloroacetate $(0.1 \mathrm{~g}, 0.8 \mathrm{mmol})$, and anhydrous $\mathrm{K}_{2} \mathrm{CO}_{3}$ $(0.44 \mathrm{~g}, 3 \mathrm{mmol})$ in DMF $(15 \mathrm{~mL})$ was stirred at $80^{\circ} \mathrm{C}$ for $5 \mathrm{~h}$. After cooling the solid product was filtered, washed with water, dried, and recrystallized from dioxane-water mixture (2:1) to give yellow 
crystals, yield $0.10 \mathrm{~g}(71.4 \%)$, m.p. $243-245{ }^{\circ} \mathrm{C}$. IR $\left(v, \mathrm{~cm}^{-1}\right)$ : 2980, 2923 (CH aliph.), 1737 (C=O), $1686(\mathrm{C}=\mathrm{O}) .{ }^{1} \mathrm{H}-\mathrm{NMR}\left(400 \mathrm{MHz}, \mathrm{CDCl}_{3}\right) \delta(\mathrm{ppm}): 1.28\left(\mathrm{t}, J=17.3,10.2 \mathrm{~Hz}, 3 \mathrm{H}, \mathrm{CH}_{3}\right), 2.78\left(\mathrm{~s}, 3 \mathrm{H}, \mathrm{CH}_{3}\right)$, 4.34-4.11 (m, 4H, 2CH $), 7.27(\mathrm{t}, 1 \mathrm{H}$, phenyl), $7.47(\mathrm{t}, 2 \mathrm{H}$, phenyl), $8.23(\mathrm{~d}, 2 \mathrm{H}$, phenyl), $9.64(\mathrm{~s}, 1 \mathrm{H}, \mathrm{NH})$. ${ }^{13} \mathrm{C}-\mathrm{NMR}\left(100 \mathrm{MHz}, \mathrm{CDCl}_{3}\right) \delta(\mathrm{ppm}): 11.79\left(\mathrm{CH}_{3}\right), 14.57\left(\mathrm{CH}_{3}\right), 33.31\left(\mathrm{CH}_{2}\right), 61.73\left(\mathrm{CH}_{2}\right), 120.21(2 \mathrm{CH})$, $126.65(\mathrm{CH}), 129.78(2 \mathrm{CH}), 130.09(\mathrm{C}), 134.73(\mathrm{C}), 138.76(\mathrm{C}), 144.31$ (C), $145.79(\mathrm{C}), 160.60(\mathrm{C}), 161.41(\mathrm{C})$, $162.100(\mathrm{C}=\mathrm{O}), 168.64(\mathrm{C}=\mathrm{O})$. Anal. calcd. for $\mathrm{C}_{18} \mathrm{H}_{16} \mathrm{~N}_{6} \mathrm{O}_{3} \mathrm{~S}$ (396.42): $\mathrm{C}, 54.54 ; \mathrm{H}, 4.07 ; \mathrm{N}, 21.20$. Found: C, $54.66 ; \mathrm{H}, 4.12 ; \mathrm{N}, 21.13 \%$.

5-Acetyl-3,6-dimethyl-1-phenyl-1H-pyrazolo[3,4-b]pyrazine (15): A mixture of amino nitroso compound 1 $(6.06 \mathrm{~g}, 30 \mathrm{mmol})$ and acetylacetone $(3.0 \mathrm{~g}, 30 \mathrm{mmol})$ in dry pyridine $(20 \mathrm{~mL})$ was heated under reflux for $8 \mathrm{~h}$. The reaction mixture was then evaporated to one-half volume and after cooling it was neutralized with dil. $\mathrm{HCl}(10 \%)$. The solid precipitate was filtered off, washed with water, and recrystallized from ethanol-water mixture (1:3) as pale brown needles, yield $6.4 \mathrm{~g}(80 \%)$, m.p. $130-132{ }^{\circ} \mathrm{C}$. IR ( $($, $\mathrm{cm}^{-1}$ ): 3050 (CH arom.), 2900 (CH aliph.), 1689 (C=O). ${ }^{1} \mathrm{H}-\mathrm{NMR}\left(400 \mathrm{MHz}, \mathrm{CDCl}_{3}\right) \delta$ (ppm): 2.70 (s, $\left.3 \mathrm{H}, \mathrm{CH}_{3}\right), 2.80\left(\mathrm{~s}, 3 \mathrm{H}, \mathrm{CH}_{3}\right), 3.00\left(\mathrm{~s}, 3 \mathrm{H}, \mathrm{CH}_{3}\right), 7.27-7.23(\mathrm{t}, 1 \mathrm{H}$, phenyl), 7.51-7.56 (t, 2H, phenyl), 8.23-8.31 (d, 2H, phenyl). ${ }^{13} \mathrm{C}-\mathrm{NMR}\left(100 \mathrm{MHz}, \mathrm{CDCl}_{3}\right) \delta(\mathrm{ppm}): 11.32\left(\mathrm{CH}_{3}\right), 25.15\left(\mathrm{CH}_{3}\right), 27.79\left(\mathrm{CH}_{3}\right)$, $120.15(2 \mathrm{CH}), 126.16(\mathrm{CH}), 129.18(2 \mathrm{CH}), 131.83(\mathrm{C}), 138.85(\mathrm{C}), 142.66(\mathrm{C}), 143.18(\mathrm{C}), 144.82(\mathrm{C})$, $154.14(\mathrm{C}), 200.54(\mathrm{C}=\mathrm{O})$. MS: $m / z\left(266 \mathrm{M}^{+}\right)$. Anal. calcd. for $\mathrm{C}_{15} \mathrm{H}_{14} \mathrm{~N}_{4} \mathrm{O}(266.12): \mathrm{C}, 67.65 ; \mathrm{H}, 5.30 ; \mathrm{N}$, 21.04. Found: $C, 67.63 ; \mathrm{H}, 5.32 ; \mathrm{N}, 21.08 \%$.

(3,6-Dimethyl-1-phenyl-5-acetyl-1H-pyrazolo[3,4-b]pyrazine)semicarbazone (16): A mixture of the acetyl derivative 5 ( $0.72 \mathrm{~g}, 3 \mathrm{mmol})$, semicarbazide hydrochloride $(0.3 \mathrm{~g}, 3 \mathrm{mmol})$, and sodium acetate $(0.6 \mathrm{~g}$, $1 \mathrm{~mol})$ in ethanol $(15 \mathrm{~mL})$ was heated under reflux for $8 \mathrm{~h}$. After cooling, the product was filtered, washed with water, and recrystallized from dioxane-water mixture (3:1) as yellow crystals, yield $0.53 \mathrm{~g}$ (93\%), m.p. $210-212{ }^{\circ} \mathrm{C} . \mathrm{IR}\left(v, \mathrm{~cm}^{-1}\right): 3487,3204\left(\mathrm{NH}_{2}+\mathrm{NH}\right), 1739(\mathrm{C}=\mathrm{O})$. MS: $m / z 323\left(\mathrm{M}^{+}\right)$. Anal. calcd. for $\mathrm{C}_{16} \mathrm{H}_{17} \mathrm{~N}_{7} \mathrm{O}$ (323.35): C, 59.43; $\mathrm{H}, 5.30 ; \mathrm{N}, 30.32$. Found: $\mathrm{C}, 59.33 ; \mathrm{H}, 5.41 ; \mathrm{N}, 30.26 \%$. No numerical data could be obtained for this compound due its insolubility in deuterated solvents.

(3,6-Dimethyl-1-phenyl-5-acetyl-1H-pyrazolo[3,4-b]pyrazine)thiosemicarbazone (17): A mixture of $\mathbf{1 5}$ (1.0 g, $4 \mathrm{mmol})$ and thiosemicarbazide $(0.34 \mathrm{~g}, 4 \mathrm{mmol})$ in ethanol $(10 \mathrm{~mL})$ was heated under reflux for $8 \mathrm{~h}$. After cooling, the solid product was filtered, washed with water, and dried. Crystallization from dioxane-water mixture (1:1) gave yellow crystals, yield $0.28 \mathrm{~g}(87 \%)$; m.p. $230-232{ }^{\circ} \mathrm{C}$; IR $\left(v, \mathrm{~cm}^{-1}\right)$ : 3434, 3237, $3152\left(\mathrm{NH}_{2}+\mathrm{NH}\right), 1690(\mathrm{C}=\mathrm{O}) .{ }^{1} \mathrm{H}-\mathrm{NMR}\left(300 \mathrm{MHz}, \mathrm{CDCl}_{3}\right) \delta(\mathrm{ppm}): 2.40\left(\mathrm{CH}_{3}\right), 2.82\left(\mathrm{CH}_{3}\right)$, $2.93\left(\mathrm{CH}_{3}\right), 6.40\left(\mathrm{~s}, 2 \mathrm{H}, \mathrm{NH}_{2}\right), 7.32-7.35(\mathrm{t}, 1 \mathrm{H}$, phenyl), 7.51-7.56 (t, $2 \mathrm{H}$, phenyl), 8.27-8.31 $(\mathrm{d}, 2 \mathrm{H}$, phenyl), $8.88(\mathrm{~s}, 1 \mathrm{H}, \mathrm{NH}) .{ }^{13} \mathrm{C}-\mathrm{NMR}\left(100 \mathrm{MHz}, \mathrm{CDCl}_{3}\right) \delta(\mathrm{ppm}): 11.49\left(\mathrm{CH}_{3}\right), 25.00\left(\mathrm{CH}_{3}\right), 27.96\left(\mathrm{CH}_{3}\right)$, $120.29(\mathrm{C}, 2 \mathrm{CH}), 126.7(\mathrm{CH}), 129.7(2 \mathrm{CH}), 131(\mathrm{C}), 138(\mathrm{C}), 142.6(\mathrm{C}), 143.8(\mathrm{C}), 144.77(\mathrm{C}), 153.8(\mathrm{C})$, 200.19 (C=S). Anal. calcd. for $\mathrm{C}_{16} \mathrm{H}_{17} \mathrm{~N}_{7} \mathrm{~S}$ (339.42): C, 56.62; H, 5.05; N, 28.89. Found: $\mathrm{C}, 56.33 ; \mathrm{H}, 5.20$; $\mathrm{N}, 28.66 \%$.

(5-Acetyl-3,6-dimethyl-1-phenyl-1H-pyrazolo[3,4-b]pyrazine)oxime (18): A mixture of $\mathbf{1 5}$ (0.25 g, $0.9 \mathrm{mmol}$ ), hydroxyl amine $(0.07 \mathrm{~g}, 1 \mathrm{mmol})$, and sodium acetate $(0.25 \mathrm{~g}, 3 \mathrm{mmol})$ in ethanol (10 $\mathrm{mL}$ ethanol) was heated under reflux for $3 \mathrm{~h}$. The reaction mixture was then evaporated to half volume and after cooling it was neutralized with dil. $\mathrm{HCl}$. The solid precipitate was filtered off, washed with water, and recrystallized from ethanol-water mixture (3-1) as fine buff needles, yield $0.16 \mathrm{~g}(89 \%)$, m.p. $223-225{ }^{\circ} \mathrm{C}$, IR $\left(v, \mathrm{~cm}^{-1}\right)$ : 3281 broad $(\mathrm{OH}), 2900$ (CH aliph.). ${ }^{1} \mathrm{H}-\mathrm{NMR}\left(400 \mathrm{MHz}, \mathrm{DMSO}-d_{6}\right) \delta$ (ppm): $2.29\left(\mathrm{~s}, 3 \mathrm{H}, \mathrm{CH}_{3}\right), 2.63\left(\mathrm{~s}, 3 \mathrm{H}, \mathrm{CH}_{3}\right) 2.81\left(\mathrm{~s}, 3 \mathrm{H}, \mathrm{CH}_{3}\right), 7.31-7.36(\mathrm{t}, 1 \mathrm{H}$, phenyl), 7.54-7.59 $(\mathrm{t}, 2 \mathrm{H}$, phenyl), 8.20-8.23 (d, 2H, phenyl), 11.59 (s, 1H, OH). ${ }^{13} \mathrm{C}-\mathrm{NMR}$ (100 MHz, DMSO) $\delta$ (ppm): 11.01 (s, $\left.3 \mathrm{H}, \mathrm{CH}_{3}\right), 13.08\left(\mathrm{~s}, 3 \mathrm{H}, \mathrm{CH}_{3}\right), 25.11\left(\mathrm{~s}, 3 \mathrm{H}, \mathrm{CH}_{3}\right), 119.52(2 \mathrm{CH}), 125.81(\mathrm{CH}), 129.29(2 \mathrm{CH}), 131.11(\mathrm{C})$, 138.69 (C), 141.37 (C), 143.08 (C), 146.15 (C), 151.87 (C), 154.14 (C). MS: $m / z\left(281 \mathrm{M}^{+}\right)$. Anal. calcd. for $\mathrm{C}_{15} \mathrm{H}_{15} \mathrm{~N}_{5} \mathrm{O}$ (281.31): C, 64.04; H, 5.37; N, 24.90. Found: C, 64.11; H, 5.42; N, 24.97\%.

(5-Acetyl-3,6-dimethyl-1-phenyl-1H-pyrazolo[3,4-b]pyrazine)hydrazone (19): A mixture of 15 (0.25 g, $0.9 \mathrm{mmol})$ and hydrazine hydrate $(0.5 \mathrm{~mL}, 80 \%)$ in ethanol $(10 \mathrm{~mL})$ was heated under reflux for 
$6 \mathrm{~h}$. After cooling the solid product was filtered, washed with water, and recrystallized from ethanol as buff needles, yield $0.2 \mathrm{~g}(87 \%)$, m.p. $136-138{ }^{\circ} \mathrm{C}$. IR $\left(v, \mathrm{~cm}^{-1}\right)$ : 3453, $3342\left(\mathrm{NH}_{2}\right), 3050$ (CH arom.). ${ }^{1} \mathrm{H}-\mathrm{NMR}\left(400 \mathrm{MHz}_{\mathrm{CDCl}}\right) \delta(\mathrm{ppm}): 2.3\left(\mathrm{~s}, 3 \mathrm{H}, \mathrm{CH}_{3}\right), 2.70\left(\mathrm{~s}, 3 \mathrm{H}, \mathrm{CH}_{3}\right) 2.90\left(\mathrm{~s}, 3 \mathrm{H}, \mathrm{CH}_{3}\right), 5.58(\mathrm{~s}$, $\left.2 \mathrm{H}, \mathrm{NH}_{2}\right), 7.27-7.31$ (t, 1H, phenyl), 7.49-7.54 (t, 2H, phenyl), 8.20-8.31 (d, 2H, phenyl). ${ }^{13} \mathrm{C}-\mathrm{NMR}$ $\left(100 \mathrm{MHz}, \mathrm{CDCl}_{3}\right) \delta(\mathrm{ppm}): 11.36\left(\mathrm{CH}_{3}\right), 12.56\left(\mathrm{CH}_{3}\right), 25.65\left(\mathrm{CH}_{3}\right), 120.03(\mathrm{CH}), 120.14(\mathrm{CH}), 125.60(\mathrm{CH})$, $129.12(\mathrm{CH}), 129.18(\mathrm{CH}), 131.52(\mathrm{C}), 139.37(\mathrm{C}), 141.94(\mathrm{C}), 143.48(\mathrm{C}), 147.35(\mathrm{C}), 147.78(\mathrm{C}), 152.34(\mathrm{C})$. MS: $m / z\left(280 \mathrm{M}^{+}\right)$. Anal. calcd. for $\mathrm{C}_{15} \mathrm{H}_{16} \mathrm{~N}_{6}$ (280.33): C, 64.27; H, 5.75; N, 29.98. Found: C, 64.11; $\mathrm{H}$, $5.42 ; \mathrm{N}, 29.93 \%$.

5-(3-Hydroxy-2,3-dihydroindol-2-on-3-ylacetyl)-3,6-dimethyl-1-phenyl-1H-pyrazolo[3,4-b]pyrazine (20): A mixture of $15(0.25 \mathrm{~g}, 0.9 \mathrm{mmol})$ and isatin $(0.14 \mathrm{~g}, 0.9 \mathrm{mmol})$ and diethyl amine $(0.5 \mathrm{~mL})$ in absolute ethanol $(15 \mathrm{~mL})$ was stirred at $\mathrm{rt}$ for overnight. The solid product obtained was filtered and recrystallized from ethanol-water mixture (1:1) as buff crystals, yield $0.18 \mathrm{~g}(90 \%)$, m.p. $167-169{ }^{\circ} \mathrm{C}$. IR $\left(v, \mathrm{~cm}^{1}\right), 3322(\mathrm{NH}), 1745(\mathrm{C}=\mathrm{O}), 1697(\mathrm{C}=\mathrm{O}) .{ }^{1} \mathrm{H}-\mathrm{NMR}\left(400 \mathrm{MHz}, \mathrm{CDCl}_{3}\right) \delta(\mathrm{ppm}): 2.77(\mathrm{~d}, J=9.7 \mathrm{~Hz}$, $\left.1 \mathrm{H}, \mathrm{CH}_{2}\right), 2.84\left(\mathrm{~s}, 6 \mathrm{H}, 2 \mathrm{CH}_{3}\right), 3.01\left(\mathrm{~d}, J=11.4 \mathrm{~Hz}, 1 \mathrm{H}, \mathrm{CH}_{2}\right), 6.90(\mathrm{~s}, 1 \mathrm{H}, \mathrm{OH}), 7.07(\mathrm{~s}, 1 \mathrm{H}, \mathrm{NH}), 7.38-7.29$ (m, 2H, Ar-H), 7.44 (d, 2H, Ar-H), 7.55 (t, 2H, Ar-H), 8.34-8.24 (m, 3H, Ar-H). ${ }^{13} \mathrm{C}-\mathrm{NMR}(100 \mathrm{MHz}$, $\left.\mathrm{CDCl}_{3}\right) \delta$ (ppm): $11.25\left(\mathrm{CH}_{3}\right), 25.02\left(\mathrm{CH}_{3}\right), 27.46\left(\mathrm{CH}_{2}\right), 45.61(\mathrm{C}), 110.11(\mathrm{C}), 115.52(\mathrm{C}), 120.31(\mathrm{CH})$, $120.40(\mathrm{CH}), 123.03(\mathrm{CH}), 124.52(\mathrm{CH}), 126.19(\mathrm{CH}), 126.41(\mathrm{CH}), 129.20(2 \mathrm{CH}), 129.98(\mathrm{CH}), 131.45(\mathrm{C})$, 138.65 (C), $142.78(\mathrm{C}), 144.86(\mathrm{C}), 148.28$ (C), $151.96(\mathrm{C}), 169.03(\mathrm{C}), 191.12(\mathrm{C}=\mathrm{O})$. Anal. calcd. for $\mathrm{C}_{23} \mathrm{H}_{21} \mathrm{~N}_{5} \mathrm{O}_{3}$ (413.4): C, 66.82; H, 4.63; N, 16.94. Found: C, 66.51; H, 5.43; N, 16.93\%.

2,3-Dihydroindol-2-on-3-ylideneacetyl-3,6-dimethyl-1-phenyl-1H-pyrazolo[3,4-b]pyrazine (21): Compound $20(0.18 \mathrm{~g}, 4 \mathrm{mmol})$ was heated in a mixture of ethanol $(7.5 \mathrm{~mL})$ and conc. $\mathrm{HCl}(2.5 \mathrm{~mL})$ for $15 \mathrm{~min}$. After cooling the solid product obtained was filtered, washed with water, and recrystallized from ethanol-dioxane mixture $(1: 3)$ as orange needles, yield $0.13 \mathrm{~g}(81 \%)$, m.p. $248-250{ }^{\circ} \mathrm{C}$. IR $\left(v, \mathrm{~cm}^{-1}\right)$, $3444(\mathrm{NH}), 3163,3074$ (CH arom.), 1716 (C=O), $1670(\mathrm{CO}-\mathrm{NH}) .{ }^{1} \mathrm{H}-\mathrm{NMR}\left(300 \mathrm{MHz}, \mathrm{CDCl}_{3}\right) \delta(\mathrm{ppm})$ : $2.90\left(\mathrm{~s}, 3 \mathrm{H}, \mathrm{CH}_{3}\right), 3.20\left(\mathrm{~s}, 3 \mathrm{H}, \mathrm{CH}_{3}\right), 6.85-6.89(\mathrm{~d}, 1 \mathrm{H}$, phenyl), $7.10(\mathrm{t}, 1 \mathrm{H}$, phenyl), 7.34-7.37 (t, 2H, phenyl), 7.52-7.55 (t, 2H, phenyl), 7.50 (s, 1H, NH), 8.30-8.33 (d, 2H, phenyl), $8.56(\mathrm{~s}, 1 \mathrm{H}, \mathrm{CH}), 8.68-8.71$ (d, 1H, phenyl). ${ }^{13} \mathrm{C}-\mathrm{NMR}\left(100 \mathrm{MHz}, \mathrm{DMSO}-d_{6}\right) \delta(\mathrm{ppm}): 11.72\left(\mathrm{CH}_{3}\right), 25.32\left(\mathrm{CH}_{3}\right), 110.80(\mathrm{CH})$, $120.43(\mathrm{CH}), 120.58(2 \mathrm{CH}), 122.29(\mathrm{CH}), 126.73(\mathrm{CH}), 126.87(\mathrm{CH}), 128.37(\mathrm{CH}), 129.87(2 \mathrm{CH}), 131.56(\mathrm{C})$, 133.90 (C), 137.79 (C), 138.71 (C), 142.55 (C), 144.31 (C), 145.09 (C), 145.88 (C), $155.16(\mathrm{C}), 168.97$ (C=O), $190.75(\mathrm{C}=\mathrm{O}) \mathrm{MS}: m / z\left(395 \mathrm{M}^{+}\right)$. Anal. calcd. for $\mathrm{C}_{23} \mathrm{H}_{19} \mathrm{~N}_{5} \mathrm{O}_{2}$ (395.4): C, 69.86; $\mathrm{H}, 4.33 ; \mathrm{N}, 17.71$. Found: C, 69.43; H, 4.64; N, 17.83\%.

N-(4-Methyl-2,3-dihydrothiazol-2-ylidene)-(5-acetyl-3,6-dimethyl-1-phenyl-1H-pyrazolo[3,4-b]pyrazine) hydrazine (22): A mixture of the thiosemicarbazone $17(0.4 \mathrm{~g}, 1 \mathrm{mmol})$, chloro acetone $(0.1 \mathrm{~mL}$, $1 \mathrm{mmol})$, and anhydrous sodium acetate $(0.5 \mathrm{~g})$ in absolute ethanol was heated under reflux for $5 \mathrm{~h}$. After cooling, the solid product obtained was filtered the reaction mixture was cooled, washed with water, and recrystallized from acetone-water mixture (1:1) as buff crystals, yield $0.05 \mathrm{~g}$ (17\%), m.p. 222-224 ${ }^{\circ} \mathrm{C}$, IR ( $\left.v, \mathrm{~cm}^{-1}\right)$ : 3178 (NH), 3067 (CH arom.), 2921, 2852 (CH aliph.). ${ }^{1} \mathrm{H}-\mathrm{NMR}$ $\left(400 \mathrm{MHz}_{\mathrm{CDCl}}\right) \delta(\mathrm{ppm}): 2.36\left(\mathrm{~s}, 3 \mathrm{H}, \mathrm{CH}_{3}\right), 2.59\left(\mathrm{~s}, 3 \mathrm{H}, \mathrm{CH}_{3}\right), 2.74\left(\mathrm{~s}, 3 \mathrm{H}, \mathrm{CH}_{3}\right), 3.06\left(\mathrm{~s}, 3 \mathrm{H}, \mathrm{CH}_{3}\right)$, $5.66(\mathrm{~s}, 1 \mathrm{H}, \mathrm{NH}), 6.29(\mathrm{~s}, 1 \mathrm{H}, \mathrm{CH}), 7.35-7.27(\mathrm{~m}, 1 \mathrm{H}$, phenyl), $7.54(\mathrm{t}, 2 \mathrm{H}$, phenyl), $8.33(\mathrm{~d}, 2 \mathrm{H}, \mathrm{phenyl})$. ${ }^{13} \mathrm{C}-\mathrm{NMR}\left(100 \mathrm{MHz}, \mathrm{CDCl}_{3}\right) \delta(\mathrm{ppm}): 11.46\left(\mathrm{CH}_{3}\right), 14.02\left(\mathrm{CH}_{3}\right), 16.71\left(\mathrm{CH}_{3}\right), 26.43\left(\mathrm{CH}_{3}\right), 103.13(\mathrm{CH})$, $120.08(2 \mathrm{CH}), 125.76(\mathrm{CH}), 128.74(2 \mathrm{CH}), 131.52(\mathrm{C}), 141.26(\mathrm{C}), 139.02(\mathrm{C}), 143.79(\mathrm{C}), 145.19(\mathrm{C})$, 146.05 (C), 149.26 (C), 152.70 (C), 169.00 (C). Anal. calcd. for $\mathrm{C}_{19} \mathrm{H}_{19} \mathrm{~N}_{7} \mathrm{~S}$ (377.47): C, 60.46; H, 5.07; N, 25.98. Found: C, 60.33; H, 5.11; N, 25.21\%.

N-(4-Phenyl-2,3-dihydrothiazol-2-ylidene)-(5-acetyl-3,6-dimethyl-1-phenyl-1H-pyrazolo[3,4-b]pyrazine) hydrazine (23): A mixture of thiosemicarbazide 17 (0.25 g, $0.7 \mathrm{mmol})$, phenacyl bromide (0.3 g, $1 \mathrm{mmol})$, and anhydrous sodium acetate $(0.25 \mathrm{~g})$ in absolute ethanol $(15 \mathrm{~mL})$ was heated under reflux for $5 \mathrm{~h}$. After cooling, the solid product was filtered, washed with water, and recrystallized from ethanol-dioxane mixture (3:1) as brown crystals, yield $0.11 \mathrm{~g}(40 \%), \mathrm{m} . \mathrm{p} .256-258{ }^{\circ} \mathrm{C}$. IR ( $v$, 
$\mathrm{cm}^{-1}$ ): 3435 (NH), 3065 (CH arom.), 2924 (CH aliph.). ${ }^{1} \mathrm{H}-\mathrm{NMR}\left(400 \mathrm{MHz}, \mathrm{CDCl}_{3}\right) \delta$ (ppm): 2.53 (s, $\left.3 \mathrm{H}, \mathrm{CH}_{3}\right), 2.73\left(\mathrm{~s}, 3 \mathrm{H}, \mathrm{CH}_{3}\right), 3.09\left(\mathrm{~s}, 3 \mathrm{H}, \mathrm{CH}_{3}\right), 6.90(\mathrm{~s}, 1 \mathrm{H}, \mathrm{CH}), 7.30-7.35(\mathrm{t}, 2 \mathrm{H}$, phenyl), 7.51-7.56 (t, 2H, phenyl), 7.39-7.44 (t, 2H, phenyl), 7.82-7.84 (d, 2H, phenyl), 8.31-8.33 (d, 2H, phenyl) 8.90 (bs, $1 \mathrm{H}, \mathrm{NH})$. MS: $\mathrm{m} / z\left(439 \mathrm{M}^{+}\right) .{ }^{13} \mathrm{C}-\mathrm{NMR}\left(100 \mathrm{MHz}, \mathrm{CDCl}_{3}\right) \delta(\mathrm{ppm}): 11.49\left(\mathrm{CH}_{3}\right), 24.85\left(\mathrm{CH}_{3}\right)$, $29.07\left(\mathrm{CH}_{3}\right), 114.30(\mathrm{CH}), 120.23(2 \mathrm{CH}), 121.02(\mathrm{CH}), 126.13(\mathrm{CH}), 127.81(\mathrm{CH}), 129.19(2 \mathrm{CH}), 130.52$ (2CH), 131.67 (C), 138.92 (C), 142.67 (C), 144.47 (2C), 144.59 (C), 144.71 (C), 154.59 (2C), 161.76 (C). Anal. calcd. for $\mathrm{C}_{24} \mathrm{H}_{21} \mathrm{~N}_{7} \mathrm{~S}$ (439.54): C, 65.58; H, 4.82; N, 22.31\%. Found: C, 65.51; H, 4.75; N, 22.21\%.

$\mathrm{N}$-(Thiazolidin-4-on-2-ylidene)-(5-Acetyl-3,6-dimethyl-1-phenyl-1H-pyrazolo[3,4-b]pyrazine) hydrazine (24): A mixture of $17(0.5 \mathrm{~g}, 1 \mathrm{mmol})$, chloro acetic acid $(0.1 \mathrm{~g}, 0.8 \mathrm{~mol})$, and anhydrous sodium acetate $(0.5 \mathrm{~g})$ in absolute ethanol was heated under reflux for $5 \mathrm{~h}$. After cooling, the solid product obtained was filtered, washed with water, and dried. Recrystallization from ethanol-dioxane mixture (1:3) gave buff crystals, yield $0.12 \mathrm{~g}(50 \%)$, m.p. $308-310^{\circ} \mathrm{C}$. IR $\left(v, \mathrm{~cm}^{-1}\right): 3446(\mathrm{NH}), 2850(\mathrm{CH}$ aliph.), $1705(\mathrm{C}=\mathrm{O})$. MS: $m / z\left(379 \mathrm{M}^{+}\right)$. Anal. calcd. for $\mathrm{C}_{18} \mathrm{H}_{17} \mathrm{~N}_{7} \mathrm{OS}$ (379.44): $\mathrm{C}, 56.98 ; \mathrm{H}, 4.52 ; \mathrm{N}, 25.84$. Found: $\mathrm{C}, 56.88 ; \mathrm{H}$, $4.65 ; \mathrm{N}, 25.91 \%$.

General procedure for the synthesis of 5-arylideneacetyl-3,6-dimethyl-1-phenyl-1H-pyrazolo[3,4-b] pyrazine (25a-k): To a mixture of equimolar amounts $(0.27,1 \mathrm{mmol})$ of 5-acetyl-3,6-dimethyl-1-phenyl- $1 \mathrm{H}$ pyrazolo[3,4-b]pyrazine (15) and an aromatic aldehyde in ethanol $(15 \mathrm{~mL})$, aqueous $\mathrm{NaOH}(0.5 \mathrm{~mL}$, $25 \%$ ) was added. The reaction mixture was stirred at room temperature for overnight, then it was poured onto ice-cold water. The solid precipitate formed was collected by filtration, washed with water, and recrystallized from dioxane-water mixture.

5-Benzylideneacetyl-3,6-dimethyl-1-phenyl-1H-pyrazolo[3,4-b]pyrazine (25a): Yield 1.68 g (84\%), m.p. 167-169 ${ }^{\circ} \mathrm{C}$. IR ( $\left.v, \mathrm{~cm}^{-1}\right)$ : 3059 (CH arom.), 2900 ( $\mathrm{CH}$ aliph.), $1670(\mathrm{C}=\mathrm{O}) .{ }^{1} \mathrm{H}-\mathrm{NMR}\left(400 \mathrm{MHz}, \mathrm{CDCl}_{3}\right)$ $\delta$ (ppm): $2.80\left(\mathrm{~s}, 3 \mathrm{H}, \mathrm{CH}_{3}\right), 3.06\left(\mathrm{~s}, 3 \mathrm{H}, \mathrm{CH}_{3}\right), 7.20-8.30\left(\mathrm{~m}, 10 \mathrm{H}\right.$, phenyl) ${ }^{13} \mathrm{C}-\mathrm{NMR}\left(100 \mathrm{MHz}, \mathrm{CDCl}_{3}\right) \delta$ (ppm): $11.49\left(\mathrm{CH}_{3}\right), 24.91\left(\mathrm{CH}_{3}\right), 120.34(2 \mathrm{CH}), 123.29(\mathrm{CH}), 126.23(\mathrm{CH}), 128.74(2 \mathrm{CH}), 128.95(2 \mathrm{CH})$, $129.23(2 \mathrm{CH}), 130.60(\mathrm{CH}, \mathrm{C}), 135.09$ (2C), 142.69 (C), $144.55(\mathrm{CH}, \mathrm{C}), 145.82(2 \mathrm{C}), 190.23(\mathrm{C}=\mathrm{O})$. MS: $m / z\left(354 \mathrm{M}^{+}\right)$. Anal. calcd. for $\mathrm{C}_{22} \mathrm{H}_{18} \mathrm{~N}_{4} \mathrm{O}$ (354): $\mathrm{C}, 74.56 ; \mathrm{H}, 5.12 ; \mathrm{N}, 15.81$. Found: $\mathrm{C}, 74.63 ; \mathrm{H}, 5.14$; $\mathrm{N}, 15.60 \%$.

3,6-Dimethyl-5-(2-hydroxylbenzylideneacetyl)-1-phenyl-1H-pyrazolo[3,4-b]pyrazine (25b): Yield $0.14 \mathrm{~g}(70 \%)$, m.p. $194-196{ }^{\circ} \mathrm{C}$. IR $\left(v, \mathrm{~cm}^{-1}\right)$ : $3213(\mathrm{OH}), 2923.40$ (CH aliph.), 1657 (C=O). ${ }^{1} \mathrm{H}-\mathrm{NMR}(400 \mathrm{MHz}$, DMSO- $\left.d_{6}\right) \delta(\mathrm{ppm}): 2.69\left(\mathrm{~s}, 3 \mathrm{H}, \mathrm{CH}_{3}\right), 2.89\left(\mathrm{~s}, 3 \mathrm{H}, \mathrm{CH}_{3}\right), 6.90(\mathrm{t}, 1 \mathrm{H}, \mathrm{Ar}-\mathrm{H}), 6.96(\mathrm{~d}, J=8.1 \mathrm{~Hz}, 1 \mathrm{H}, \mathrm{CH})$, $7.30(\mathrm{t}, 1 \mathrm{H}, \mathrm{Ar}-\mathrm{H}), 7.37(\mathrm{t}, 1 \mathrm{H}, \mathrm{Ar}-\mathrm{H}), 7.59(\mathrm{t}, 2 \mathrm{H}, \mathrm{Ar}-\mathrm{H}), 7.70(\mathrm{~d}, J=7.6 \mathrm{~Hz}, 1 \mathrm{H}, \mathrm{CH}), 8.03(\mathrm{~s}, 2 \mathrm{H}, \mathrm{Ar}-\mathrm{H})$, $8.23\left(\mathrm{~d}, 2 \mathrm{H}\right.$, phenyl), $10.32(\mathrm{~s}, 1 \mathrm{H}, \mathrm{OH}) \cdot{ }^{13} \mathrm{C}-\mathrm{NMR}\left(100 \mathrm{MHz}, \mathrm{DMSO}-d_{6}\right): 11.59\left(\mathrm{CH}_{3}\right), 24.68\left(\mathrm{CH}_{3}\right)$, $116.80(\mathrm{C}), 120.00(\mathrm{CH}), 120.31(2 \mathrm{CH}), 121.73(\mathrm{C}), 123.33(\mathrm{CH}), 126.67(\mathrm{CH}), 129.61(\mathrm{CH}), 129.82(2 \mathrm{CH})$, $131.49(\mathrm{CH}), 132.70(\mathrm{C}), 138.87(\mathrm{C}), 140.71(\mathrm{C}), 142.60(\mathrm{C}), 144.73(\mathrm{CH}), 145.18(\mathrm{C}), 154.09(\mathrm{C}), 157.95(\mathrm{CH})$, $190.71(\mathrm{C}=\mathrm{O})$. Anal. calcd. for $\mathrm{C}_{22} \mathrm{H}_{18} \mathrm{~N}_{4} \mathrm{O}_{2}$ (370.40): C, 71.34; $\mathrm{H}, 4.90 ; \mathrm{N}, 15.13$. Found: $\mathrm{C}, 71.23 ; \mathrm{H}$, $4.85 ; \mathrm{N}, 15.25 \%$.

3,6-Dimethyl-5-(2-nitrobenzylideneacetyl)-1-phenyl-1H-pyrazolo[3,4-b]pyrazine (25c): Yield $0.17 \mathrm{~g}(85 \%)$, m.p. $263-265^{\circ} \mathrm{C}$. IR $\left(v, \mathrm{~cm}^{-1}\right): 3066$ (CH arom.), $1672(\mathrm{C}=\mathrm{O}) .{ }^{1} \mathrm{H}-\mathrm{NMR}\left(400 \mathrm{MHz}, \mathrm{CDCl}_{3}\right) \delta$ (ppm): $2.84\left(\mathrm{~s}, 3 \mathrm{H}, \mathrm{CH}_{3}\right), 3.10\left(\mathrm{~s}, 3 \mathrm{H}, \mathrm{CH}_{3}\right), 7.37(\mathrm{~d}, J=6.5 \mathrm{~Hz}, 2 \mathrm{H}, \mathrm{CH}, \mathrm{Ar}-\mathrm{H}), 7.57(\mathrm{t}, 2 \mathrm{H}, \mathrm{Ar}-\mathrm{H}), 7.90(\mathrm{t}, 3 \mathrm{H}$, Ar-H), 8.41-8.30 (m, 4H, CH, Ar-H). ${ }^{13} \mathrm{C}-\mathrm{NMR}\left(100 \mathrm{MHz}, \mathrm{CDCl}_{3}\right) \delta(\mathrm{ppm}): 11.52\left(\mathrm{CH}_{3}\right), 25.11\left(\mathrm{CH}_{3}\right)$, $120.38(2 \mathrm{CH}), 124.20(2 \mathrm{CH}), 126.40(\mathrm{CH}), 126.85(\mathrm{CH}), 129.18(2 \mathrm{CH}), 129.26(2 \mathrm{CH}, \mathrm{C}), 138.76(\mathrm{C})$, $140.86(2 \mathrm{C}), 141.31(\mathrm{C}), 144.93(\mathrm{CH}, \mathrm{C}), 155.35(2 \mathrm{C}), 189.20(\mathrm{C}=\mathrm{O})$. Anal. calcd. For $\mathrm{C}_{22} \mathrm{H}_{17} \mathrm{~N}_{5} \mathrm{O}_{3}(399.40)$ : C, 66.16; H, 4.29; N, 17.53. Found: C, 66.22; H, 4.18; N, 17.41\%.

3,6-Dimethyl-5-(4-nitrobenzylideneacetyl)-1-phenyl-1H-pyrazolo[3,4-b]pyrazine (25d): Yield $0.12 \mathrm{~g}(80 \%)$, m.p. $263-265^{\circ} \mathrm{C}$. IR $\left(v, \mathrm{~cm}^{-1}\right)$ : 3051 (CH arom.), $1672(\mathrm{C}=\mathrm{O}) .{ }^{1} \mathrm{H}-\mathrm{NMR}\left(400 \mathrm{MHz}, \mathrm{CDCl}_{3}\right) \delta$ (ppm): $2.84\left(\mathrm{~s}, 3 \mathrm{H}, \mathrm{CH}_{3}\right), 3.10\left(\mathrm{~s}, 3 \mathrm{H}, \mathrm{CH}_{3}\right), 7.35-7.37(\mathrm{t}, J=7.4 \mathrm{~Hz}, 1 \mathrm{H}, \mathrm{CH}), 7.55-7.59(\mathrm{t}, 2 \mathrm{H}, \mathrm{Ar}-\mathrm{H}), 7.87-7.93(\mathrm{t}$, $J=11.9 \mathrm{~Hz}, 2 \mathrm{H}, \mathrm{CH}, \mathrm{Ar}-\mathrm{H}), 8.32-8.40(\mathrm{~m}, 5 \mathrm{H}, \mathrm{Ar}-\mathrm{H}) .{ }^{13} \mathrm{C}-\mathrm{NMR}\left(100 \mathrm{MHz}, \mathrm{CDCl}_{3}\right) \delta(\mathrm{ppm}): 11.52\left(\mathrm{CH}_{3}\right)$, $25.11\left(\mathrm{CH}_{3}\right), 120.37(2 \mathrm{CH}), 124.21(2 \mathrm{CH}), 126.40(\mathrm{CH}), 126.86(\mathrm{CH}), 129.18(2 \mathrm{CH}), 129.26(2 \mathrm{CH})$, 
$131.89(\mathrm{C}), 138.75(\mathrm{C}), 140.86(\mathrm{CH}), 141.31(\mathrm{C}), 142.67(\mathrm{C}), 143.25(\mathrm{C}), 144.94(\mathrm{C}), 148.57(\mathrm{C}), 155.35(\mathrm{C})$, $189.20(\mathrm{C}=\mathrm{O})$. Anal. calcd. for $\mathrm{C}_{22} \mathrm{H}_{17} \mathrm{~N}_{5} \mathrm{O}_{3}$ (399.40): $\mathrm{C}, 66.16 ; \mathrm{H}, 4.29 ; \mathrm{N}, 17.53$. Found: $\mathrm{C}, 66.11 ; \mathrm{H}$, $4.17 ; \mathrm{N}, 17.42 \%$.

3,6-Dimethyl-5-(3-nitrobenzylideneacetyl)-1-phenyl-1H-pyrazolo[3,4-b]pyrazine (25e): Yield 0.15 g (75\%); m.p. $223-225^{\circ} \mathrm{C}$; IR (v, cm ${ }^{-1}$ ): 3086 (CH arom.), 2925 (CH aliph.), 1674 (C=O); ${ }^{1} \mathrm{H}-\mathrm{NMR}(400 \mathrm{MHz}$, $\left.\mathrm{CDCl}_{3}\right) \delta$ (ppm): $2.85\left(\mathrm{~s}, 3 \mathrm{H}, \mathrm{CH}_{3}\right), 3.10\left(\mathrm{~s}, 3 \mathrm{H}, \mathrm{CH}_{3}\right), 7.36(\mathrm{t}, 1 \mathrm{H}, \mathrm{Ar}-\mathrm{H}), 7.57(\mathrm{t}, 2 \mathrm{H}, \mathrm{Ar}-\mathrm{H}), 7.66(\mathrm{t}, 1 \mathrm{H}$, Ar-H), 7.91 (d, J = 16.0 Hz, 1H, CH), 8.02 (d, J = 7.5 Hz, 1H, CH), 8.42-8.27 (m, 4H, Ar-H), 8.59 (s, $1 \mathrm{H}, \mathrm{Ar}-\mathrm{H}) .{ }^{13} \mathrm{C}-\mathrm{NMR}\left(100 \mathrm{MHz}, \mathrm{CDCl}_{3}\right) \delta(\mathrm{ppm}): 11.58\left(\mathrm{CH}_{3}\right), 25.09\left(\mathrm{CH}_{3}\right), 120.36(2 \mathrm{CH}), 122.80(\mathrm{CH})$, $124.64(\mathrm{CH}), 125.79(\mathrm{CH}), 126.35(\mathrm{CH}), 129.25(2 \mathrm{CH}), 129.97(\mathrm{CH}), 131.89(\mathrm{CH}), 134.38(\mathrm{C}), 136.93(\mathrm{C})$, 138.73 (C), 141.06 (C), 142.67 (C), 143.36 (C), 144.98 (C), 148.97 (C), 155.25 (C), 189.29 (C=O). Anal. calcd. For $\mathrm{C}_{22} \mathrm{H}_{17} \mathrm{~N}_{5} \mathrm{O}_{3}$ (399.40): C, 66.16; H, 4.29; N, 17.53. Found: $\mathrm{C}, 66.24 ; \mathrm{H}, 4.17 ; \mathrm{N}, 17.66 \%$.

3,6-Dimethyl-5-(4-cyanobenzylideneacetyl)-1-phenyl-1H-pyrazolo[3,4-b]pyrazine (25f): Yield 0.16 g (80\%), m.p. $254-256{ }^{\circ} \mathrm{C}$. IR ( $\left.v, \mathrm{~cm}^{-1}\right): 3079$ (CH arom.), $2224(\mathrm{CN}), 1672$ (C=O). ${ }^{1} \mathrm{H}-\mathrm{NMR}\left(400 \mathrm{MHz}, \mathrm{CDCl}_{3}\right)$ $\delta$ (ppm): $2.84\left(\mathrm{~s}, 3 \mathrm{H}, \mathrm{CH}_{3}\right), 3.09\left(\mathrm{~s}, 3 \mathrm{H}, \mathrm{CH}_{3}\right), 7.37(\mathrm{t}, 1 \mathrm{H}, \mathrm{Ar}-\mathrm{H}), 7.57(\mathrm{~d}, J=7.4 \mathrm{~Hz}, 2 \mathrm{H}, \mathrm{CH}), 7.81(\mathrm{~m}$, 6H, Ar-H), 8.39-8.30 (d, 2H, Ar-H). ${ }^{13} \mathrm{C}-\mathrm{NMR}\left(100 \mathrm{MHz}, \mathrm{CDCl}_{3}\right) \delta(\mathrm{ppm}): 11.50\left(\mathrm{CH}_{3}\right), 25.10\left(\mathrm{CH}_{3}\right)$, $113.45(\mathrm{C}), 118.46(\mathrm{C} \equiv \mathrm{N}), 120.32(2 \mathrm{CH}), 126.16(\mathrm{CH}), 126.94(\mathrm{CH}), 128.94(\mathrm{CH}), 129.24(2 \mathrm{CH}), 130.02(\mathrm{CH})$, $131.85(\mathrm{CH}), 132.66(\mathrm{CH}), 138.77(\mathrm{C}), 139.45(\mathrm{C}), 140.34(\mathrm{C}), 141.42(\mathrm{C}), 142.64(\mathrm{C}), 143.32(\mathrm{C}), 144.89(\mathrm{CH})$, $155.28(\mathrm{C}), 189.27(\mathrm{C}=\mathrm{O})$. Anal. calcd. for $\mathrm{C}_{23} \mathrm{H}_{17} \mathrm{~N}_{5} \mathrm{O}$ (379.41): C, 72.81; H, 4.52; N, 18.46. Found: C, 72.76; H, 4.40; N, $18.55 \%$.

3,6-Dimethyl-5-(4-methoxybenzylideneacetyl)-1-phenyl-1H-pyrazolo[3,4-b]pyrazine (25g): Yield 0.18 g (90\%), m.p. $210-212{ }^{\circ} \mathrm{C}$. IR ( $\left.v, \mathrm{~cm}^{-1}\right)$ : 3069 (CH arom.), 2934, 2836 (CH aliph.), 1663 (C=O); ${ }^{1} \mathrm{H}-\mathrm{NMR}$ $\left(400 \mathrm{MHz} \mathrm{CDCl}_{3}\right) \delta(\mathrm{ppm}): 2.82\left(\mathrm{~s}, 3 \mathrm{H}, \mathrm{CH}_{3}\right), 3.05\left(\mathrm{~s}, 3 \mathrm{H}, \mathrm{CH}_{3}\right), 3.89\left(\mathrm{~s}, 3 \mathrm{H}, \mathrm{CH}_{3}\right), 6.98(\mathrm{~d}, 2 \mathrm{H}, \mathrm{Ar}-\mathrm{H})$, $7.34(\mathrm{t}, 1 \mathrm{H}, \mathrm{Ar}-\mathrm{H}), 7.56(\mathrm{t}, 2 \mathrm{H}, \mathrm{Ar}-\mathrm{H}), 7.69(\mathrm{~d}, 2 \mathrm{H}, \mathrm{Ar}-\mathrm{H}), 7.84(\mathrm{~d}, 1 \mathrm{H}, \mathrm{CH}), 8.00(\mathrm{~d}, J=15.9 \mathrm{~Hz}, 1 \mathrm{H}$, $\mathrm{CH}), 8.34$ (d, 2H, Ar-H). ${ }^{13} \mathrm{C}-\mathrm{NMR}\left(100 \mathrm{MHz}, \mathrm{CDCl}_{3}\right) \delta(\mathrm{ppm}): 11.49\left(\mathrm{CH}_{3}\right), 24.85\left(\mathrm{CH}_{3}\right), 55.41\left(\mathrm{CH}_{3}\right)$, $114.40(2 \mathrm{CH}), 120.23(2 \mathrm{CH}), 121.02(\mathrm{C}), 126.13(\mathrm{CH}), 127.81(\mathrm{CH}), 129.19(2 \mathrm{CH}), 130.52(2 \mathrm{CH}), 131(\mathrm{C})$, 138.92 (C), 142.67 (C), 144.47 (CH), 144.59 (C), 144.71 (C), 154.59 (C), 161.76 (C), 190.26 (C=O). Anal. calcd. for $\mathrm{C}_{23} \mathrm{H}_{20} \mathrm{~N}_{4} \mathrm{O}_{2}$ (384.43): C, 71.86; H, 5.24; N, 14.57. Found: C, 71.75; H, 5.33; N, 14.63\%.

3,6-Dimethyl-5-(4-N,N-dimethylaminobenzylideneacetyl)-1-phenyl-1H-pyrazolo[3,4-b]pyrazine (25h): Yield $0.14 \mathrm{~g}(70 \%)$, m.p. $227-229{ }^{\circ} \mathrm{C}$. IR $\left(v, \mathrm{~cm}^{-1}\right)$ : 2921 (CH aliph.), 1659 (C=O); ${ }^{1} \mathrm{H}-\mathrm{NMR}\left(400 \mathrm{MHz}, \mathrm{CDCl}_{3}\right) \delta$ (ppm): $2.81\left(\mathrm{~s}, 3 \mathrm{H}, \mathrm{CH}_{3}\right), 3.03\left(\mathrm{~s}, 3 \mathrm{H}, \mathrm{CH}_{3}\right), 3.08\left(\mathrm{~s}, 6 \mathrm{H}, 2 \mathrm{CH}_{3}\right), 6.79(\mathrm{~d}, 2 \mathrm{H}, \mathrm{Ar}-\mathrm{H}), 7.38-7.25(\mathrm{t}, 1 \mathrm{H}, \mathrm{Ar}-\mathrm{H})$, 7.69-7.50 (m, 4H, CH, Ar-H), 7.83 (s, 2H, Ar-H), 8.34 (d, 2H, phenyl). ${ }^{13} \mathrm{C}-\mathrm{NMR}\left(100 \mathrm{MHz}, \mathrm{CDCl}_{3}\right)$ $\delta$ (ppm): $11.48\left(\mathrm{CH}_{3}\right), 24.64\left(\mathrm{CH}_{3}\right), 40.08\left(2 \mathrm{CH}_{3}\right), 111.78(2 \mathrm{C}), 118.36(\mathrm{C}), 120.17(2 \mathrm{CH}), 122.77(\mathrm{CH})$, $126.02(\mathrm{CH}), 129.16(2 \mathrm{CH}), 130.75(2 \mathrm{CH}), 131.57(\mathrm{C}), 139.06(\mathrm{C}), 142.81(\mathrm{C}), 144.61(\mathrm{C}), 146.06(2 \mathrm{C})$, $152.12(\mathrm{CH}), 154.100(\mathrm{C}), 190.60(\mathrm{C}=\mathrm{O})$. Anal. calcd. For $\mathrm{C}_{24} \mathrm{H}_{23} \mathrm{~N}_{5} \mathrm{O}$ (397.47): C, 72.52; H, 5.83; N, 17.62. Found: C, 72.63; H, 5.94; N, 17.45\%.

3,6-Dimethyl-5-(4-chlorobenzylideneacetyl)-1-phenyl-1H-pyrazolo[3,4-b]pyrazine (25i): Yield 0.23 g (92\%), m.p. 228-230 ${ }^{\circ} \mathrm{C}$; IR ( $\left.v, \mathrm{~cm}^{-1}\right): 3081$ (CH arom.), $1669(\mathrm{C}=\mathrm{O}) ;{ }^{1} \mathrm{H}-\mathrm{NMR}\left(400 \mathrm{MHz}, \mathrm{CDCl}_{3}\right) \delta(\mathrm{ppm})$ : $2.82\left(\mathrm{~s}, 3 \mathrm{H}, \mathrm{CH}_{3}\right), 3.07\left(\mathrm{~s}, 3 \mathrm{H}, \mathrm{CH}_{3}\right), 7.33-7.37(\mathrm{t}, 1 \mathrm{H}, \mathrm{Ar}-\mathrm{H}), 7.43-7.45(\mathrm{~d}, 2 \mathrm{H}, \mathrm{Ar}-\mathrm{H}), 7.54-7.58(\mathrm{t}, 2 \mathrm{H}$, Ar-H), 7.65-7.67 (d, 2H, Ar-H), 7.81-7.85 (d, J = 16.0 Hz, 1H, CH), 8.14-8.18 (d, J = 16.0 Hz, 1H, CH), 8.32-8.34 (d, 2H, Ar-H). ${ }^{13} \mathrm{C}-\mathrm{NMR}\left(100 \mathrm{MHz}, \mathrm{CDCl}_{3}\right) \delta(\mathrm{ppm}): 11.50\left(\mathrm{CH}_{3}\right), 24.98\left(\mathrm{CH}_{3}\right), 120.31(2 \mathrm{CH})$, $123.61(\mathrm{CH}), 126.26(\mathrm{CH}), 129.23(2 \mathrm{CH}), 129.63(2 \mathrm{CH}), 129.86(2 \mathrm{CH}), 131.77(\mathrm{C}), 133.60(\mathrm{C}), 136.46(\mathrm{C})$, $138.85(\mathrm{C}), 142.67(\mathrm{C}), 142.85(\mathrm{C}), 43.92(\mathrm{C}), 144.82(\mathrm{CH}), 154.96(\mathrm{C}), 189.83(\mathrm{C})$. Anal. calcd. for $\mathrm{C}_{22} \mathrm{H}_{17} \mathrm{ClN}_{4} \mathrm{O}$ (388.85): C, 67.95; H, 4.41; Cl, 9.12; N, 14.41. Found: C, 67.8; H, 4.55; Cl, 9.07; N, $14.54 \%$.

3,6-Dimethyl-5-(3,4-Dimethoxybenzylideneacetyl)-1-phenyl-1H-pyrazolo[3,4-b]pyrazine (25j): Yield 0.17 g (85\%), m.p. 199-201 ${ }^{\circ} \mathrm{C}$. IR ( $\left.v, \mathrm{~cm}^{-1}\right)$ : 3078 (CH arom.), 2988, 2837 (CH aliph.), $1663(\mathrm{C}=\mathrm{O}) ;{ }^{1} \mathrm{H}-\mathrm{NMR}$ $\left(400 \mathrm{MHz}_{2} \mathrm{CDCl}_{3}\right) \delta(\mathrm{ppm}): 2.82\left(\mathrm{~s}, 3 \mathrm{H}, \mathrm{CH}_{3}\right), 3.05\left(\mathrm{~s}, 3 \mathrm{H}, \mathrm{CH}_{3}\right), 3.98\left(\mathrm{~d}, J=9.8 \mathrm{~Hz}, 6 \mathrm{H}, 2 \mathrm{CH}_{3}\right), 6.95(\mathrm{~d}$, $J=8.2 \mathrm{~Hz}, 1 \mathrm{H}, \mathrm{CH}), 7.40-7.24(\mathrm{~m}, 3 \mathrm{H}, \mathrm{CH}, \mathrm{Ar}-\mathrm{H}), 7.56(\mathrm{t}, 2 \mathrm{H}, \mathrm{Ar}-\mathrm{H}), 7.82(\mathrm{~d}, 1 \mathrm{H}, \mathrm{Ar}-\mathrm{H}), 7.96(\mathrm{~d}, 1 \mathrm{H}$, $\mathrm{Ar}-\mathrm{H}), 8.34$ (d, 2H, Ar-H). Anal. calcd. for $\mathrm{C}_{24} \mathrm{H}_{22} \mathrm{~N}_{4} \mathrm{O}_{3}$ (414.46): C, 69.55; H, 5.35; N, 13.52. Found: 
C, $69.43 ; \mathrm{H}, 5.47 ; \mathrm{N}, 13.67 \%$. No ${ }^{13} \mathrm{C}-\mathrm{NMR}$ data could be obtained due to the precipitation of the compound while running the measurement.

3,6-Dimethyl-5-(Ethene-2-ylbenzylideneacetyl)-1-phenyl-1H-pyrazolo[3,4-b]pyrazine (25k): Yield $0.17 \mathrm{~g}$ (85\%), m.p. $211-213{ }^{\circ} \mathrm{C}$, IR (v, cm $\left.{ }^{-1}\right)$ : 2922 (CH aliph.), 1662 (C=O); ${ }^{1} \mathrm{H}-\mathrm{NMR}\left(400 \mathrm{MHz}, \mathrm{CDCl}_{3}\right)$ $\delta$ (ppm): $2.81\left(\mathrm{~s}, 3 \mathrm{H}, \mathrm{CH}_{3}\right), 3.05(\mathrm{~s}, 3 \mathrm{H}, \mathrm{CH}), 7.13(\mathrm{~m}, 2 \mathrm{H}, \mathrm{CH}, \mathrm{Ar}-\mathrm{H}), 7.43-7.33(\mathrm{~m}, 4 \mathrm{H}, \mathrm{CH}, \mathrm{Ar}-\mathrm{H})$, $7.55(\mathrm{~d}, 4 \mathrm{H}, \mathrm{CH}, \mathrm{Ar}-\mathrm{H}), 7.70(\mathrm{t}, 2 \mathrm{H}, \mathrm{Ar}-\mathrm{H}), 8.33(\mathrm{~d}, 2 \mathrm{H}, \mathrm{Ar}-\mathrm{H}) .{ }^{13} \mathrm{C}-\mathrm{NMR}\left(100 \mathrm{MHz}, \mathrm{CDCl}_{3}\right) \delta$ (ppm): $11.45\left(\mathrm{CH}_{3}\right), 24.88\left(\mathrm{CH}_{3}\right), 120.32(2 \mathrm{CH}), 126.20(\mathrm{CH}), 126.84(\mathrm{CH}), 127.35(2 \mathrm{CH}), 128.86(2 \mathrm{CH})$, $129.22(2 \mathrm{CH}), 136.20(\mathrm{CH}), 138.90(\mathrm{C}), 142.02(\mathrm{CH}, \mathrm{C}), 144.29(2 \mathrm{C}), 144.58(\mathrm{CH}, \mathrm{C}), 144.78(\mathrm{CH}, \mathrm{C})$, $154.72(\mathrm{C}), 189.32(\mathrm{C}=\mathrm{O})$. Anal. calcd. for $\mathrm{C}_{24} \mathrm{H}_{20} \mathrm{~N}_{4} \mathrm{O}$ for (380.44): $\mathrm{C}, 75.77 ; \mathrm{H}, 5.30 ; \mathrm{N}, 14.73$. Found: $\mathrm{C}$, 75.83; $\mathrm{H}, 5.18 ; \mathrm{N}, 14.66 \%$.

3,6-Dimethyl-5-(5-phenyl-4,5-dihydro-1H-pyrazol-3-yl)-1-phenyl-1H-pyrazolo[3,4-b]pyrazine (26): A mixture of chalcone $25 \mathrm{a}(0.25 \mathrm{~g}, 7 \mathrm{mmol})$, hydrazine hydrate $(80 \%, 0.3 \mathrm{~mL})$, in ethanol $(15 \mathrm{~mL})$ was heated under reflux for $10 \mathrm{~h}$. After cooling the solid product obtained was filtered, washed with water, and recrystallized from dioxane-water mixture (3:1) as yellow crystals, yield $0.23 \mathrm{~g} \mathrm{(50 \% ),} \mathrm{m.p.}$ 146-148 ${ }^{\circ} \mathrm{C}$. IR $\left(v, \mathrm{~cm}^{-1}\right): 3351$ (NH), 2921 (CH aliph.). ${ }^{1} \mathrm{H}-\mathrm{NMR}\left(400 \mathrm{MHz}, \mathrm{CDCl}_{3}\right) \delta$ (ppm): 2.63 (s, $\left.3 \mathrm{H}, \mathrm{CH}_{3}\right), 3.10\left(\mathrm{~s}, 3 \mathrm{H}, \mathrm{CH}_{3}\right), 3.73\left(\mathrm{~s}, 3 \mathrm{H}, \mathrm{CH}, \mathrm{CH}_{2}\right), 5.08(\mathrm{~s}, 1 \mathrm{H}, \mathrm{NH}), 7.33(\mathrm{~m}, 3 \mathrm{H}$, phenyl), 7.45-7.37 (m, 3H, phenyl), $7.55\left(\mathrm{t}, 2 \mathrm{H}\right.$, phenyl), $8.32\left(\mathrm{~d}, 2 \mathrm{H}\right.$, phenyl). ${ }^{13} \mathrm{C}-\mathrm{NMR}\left(100 \mathrm{MHz}, \mathrm{CDCl}_{3}\right) \delta(\mathrm{ppm})$ : $11.27\left(\mathrm{CH}_{3}\right), 25.00\left(\mathrm{CH}_{3}\right), 43.00\left(\mathrm{CH}_{2}\right), 67.10(\mathrm{CH}), 120.04(2 \mathrm{CH}), 125.69(2 \mathrm{CH}), 126.3(2 \mathrm{CH}), 128.86$ (2CH), $129.1(2 \mathrm{CH}), 129.8$ (C), 131 (C), 139.7 (C), 142 (C), 143.3 (C), 143.5 (C), 144.5 (C), 154 (C). Anal. calcd. for $\mathrm{C}_{22} \mathrm{H}_{20} \mathrm{~N}_{6}$ (368.43): C, 71.72; $\mathrm{H}, 5.47 ; \mathrm{N}, 22.81$. Found: $\mathrm{C}, 71.63 ; \mathrm{H}, 5.53 ; \mathrm{N}, 22.60 \%$.

3,6-Dimethyl-5-(5-phenyl-4,5-dihydro-1-phenyl-1H-pyrazol-3-yl)-1-phenyl-1H-pyrazolo[3,4-b]pyrazine (27): A mixture of chalcone $25 \mathrm{a}(0.25 \mathrm{~g}, 7 \mathrm{mmol})$, phenyl hydrazine $(0.1 \mathrm{~g}, 7 \mathrm{mmol})$ in ethanol $(15 \mathrm{~mL})$ was heated under reflux for $15 \mathrm{~min}$. After cooling, the reaction mixture was filtered, washed with water, and recrystallized from ethanol as yellow crystals, yield $0.15 \mathrm{~g}(62 \%)$, m.p. $162-164{ }^{\circ} \mathrm{C}$. IR $\left(v, \mathrm{~cm}^{-1}\right)$ : 2900 (CH aliph.); ${ }^{1} \mathrm{H}-\mathrm{NMR}\left(400 \mathrm{MHz}, \mathrm{CDCl}_{3}\right) \delta(\mathrm{ppm}): 2.81\left(\mathrm{~s}, 3 \mathrm{H}, \mathrm{CH}_{3}\right), 3.06\left(\mathrm{~s}, 3 \mathrm{H}, \mathrm{CH}_{3}\right), 3.70(\mathrm{t}, 1 \mathrm{H}$, $\mathrm{CH}), 7.34-7.44(\mathrm{~d}, 2 \mathrm{H}$, phenyl), 7.45-7.46 (t, 2H, phenyl), 7.52-7.58 (t, 2H, phenyl), 7.71-7.74 $(\mathrm{m}, 6 \mathrm{H}$, phenyl), $7.85\left(\mathrm{~d}, 1 \mathrm{H}, \mathrm{CH}_{2}\right), 8.15\left(\mathrm{~d}, 1 \mathrm{H}, \mathrm{CH}_{2}\right), 8.30-8.33\left(\mathrm{~d}, 3 \mathrm{H}\right.$, phenyl). ${ }^{13} \mathrm{C}-\mathrm{NMR}\left(100 \mathrm{MHz}, \mathrm{CDCl}_{3}\right)$ $\delta$ (ppm): $11.50\left(\mathrm{CH}_{3}\right), 24.93\left(\mathrm{CH}_{3}\right), 38.13\left(\mathrm{CH}_{2}\right), 59.51(\mathrm{CH}), 102.18(\mathrm{C}), 120.33(2 \mathrm{CH}), 123.25(2 \mathrm{CH})$, $126.23(2 \mathrm{CH}), 128.73(2 \mathrm{CH}), 128.94(2 \mathrm{CH}), 129.23(2 \mathrm{CH}), 130.60(2 \mathrm{CH}), 131.75(\mathrm{CH}), 135.06(\mathrm{C}), 138.86(\mathrm{C})$, 142.68 (C), 144.20 (C), 144.55 (2C), 144.82 (C), 154.82 (C). MS: $m / z\left(443 \mathrm{M}^{+}-1\right)$. Anal. calcd. for $\mathrm{C}_{28} \mathrm{H}_{24} \mathrm{~N}_{6}$ (444.5): C, 75.65; H, 5.44; N, 18.91. Found: C, 75.41; H, 5.21; N, 19.20\%.

3,6-Dimethyl-5-(5-phenyl-4,5-dihydro[1,2]oxazol-3-yl)-1-phenyl-1H-pyrazolo[3,4-b]pyrazine (28): A mixture of chalcone $25 \mathrm{a}(0.25 \mathrm{~g}, 7 \mathrm{mmol})$, hydroxylamine hydrochloride $(0.1 \mathrm{~g}, 7 \mathrm{mmol})$, and sodium acetate $(0.3 \mathrm{~g}, 2 \mathrm{mmol})$ in ethanol $(10 \mathrm{~mL})$ was heated under reflux for $6 \mathrm{~h}$. The reaction mixture was then evaporated to half of its volume. After cooling, it was neutralized with dil. $\mathrm{HCl}$ and the solid precipitate was filtered off, washed with water, and recrystallized from ethanol-water mixture (1:1), yield 0.17 g (74\%), m.p. $200-202{ }^{\circ} \mathrm{C}$. IR $\left(v, \mathrm{~cm}^{-1}\right): 2926$ (CH aliph.). ${ }^{1} \mathrm{H}-\mathrm{NMR}\left(400 \mathrm{MHz}, \mathrm{CDCl}_{3}\right) \delta$ (ppm): 2.69 $\left(\mathrm{s}, 3 \mathrm{H}, \mathrm{CH}_{3}\right), 2.73\left(\mathrm{~s}, 3 \mathrm{H}, \mathrm{CH}_{3}\right), 2.79\left(\mathrm{~d}, 1 \mathrm{H}, \mathrm{CH}_{2}\right), 3.14\left(\mathrm{~d}, 1 \mathrm{H}, \mathrm{CH}_{2}\right), 3.72-3.77(\mathrm{t}, 1 \mathrm{H}, \mathrm{CH}), 7.28-8.33$ (m, 10H, Ar-H). ${ }^{13} \mathrm{C}-\mathrm{NMR}\left(100 \mathrm{MHz}, \mathrm{CDCl}_{3}\right) \delta(\mathrm{ppm}): 11.38\left(\mathrm{CH}_{3}\right), 23.15\left(\mathrm{CH}_{3}\right), 46.08\left(\mathrm{CH}_{2}\right), 102.88$ (CH cyclic), $106.66(\mathrm{C}), 120.33(2 \mathrm{CH}), 123(\mathrm{CH}), 125.95(\mathrm{CH}), 126.17(\mathrm{CH}), 126.95(\mathrm{CH}), 128.71(\mathrm{CH})$, $128.92(\mathrm{CH}), 129.00(\mathrm{CH}), 129.19(\mathrm{CH}), 130(\mathrm{C}), 139.01(\mathrm{C}), 144.53(\mathrm{C}), 151.42(\mathrm{C}), 156.52(\mathrm{C}), 162.43(\mathrm{C})$, 169.64 (C). Anal. calcd. for $\mathrm{C}_{22} \mathrm{H}_{19} \mathrm{~N}_{5} \mathrm{O}$ (369.42): C, 71.53; H, 5.18; N, 18.96. Found: $\mathrm{C}, 71.41 ; \mathrm{H}, 5.21 ; \mathrm{N}$, $18.91 \%$.

5-Phenyl-4,5-dihydro-3-(3,6-dimethyl-1-phenyl-1H-pyrazolo[3,4-b]pyrazine-5-yl) pyrazole-1-carbothioamide (29): A mixture of compound $25 \mathrm{a}(0.25 \mathrm{~g}, 7 \mathrm{mmol})$ and thiosemicarbazide $(0.1 \mathrm{~g}, 7 \mathrm{mmol})$ in ethanolic $\mathrm{NaOH}(25 \%, 10 \mathrm{~mL})$ was heated under reflux for $3 \mathrm{~h}$. After cooling, the reaction mixture was filtered, washed with water, and recrystallized from ethanol-dioxane mixture (1:1) as yellow crystals, yield 0.08 g (50\%), m.p. $234-236{ }^{\circ} \mathrm{C}$. IR ( $\left.v, \mathrm{~cm}^{-1}\right)$ : 3407, $3280\left(\mathrm{NH}_{2}\right), 3165$ ( $\mathrm{CH}$ arom.), 2851 (CH aliph.). 
${ }^{1} \mathrm{H}-\mathrm{NMR}\left(400 \mathrm{MHz}, \mathrm{CDCl}_{3}\right) \delta(\mathrm{ppm}): 2.67\left(\mathrm{~s}, 3 \mathrm{H}, \mathrm{CH}_{3}\right), 2.70\left(\mathrm{~s}, 3 \mathrm{H}, \mathrm{CH}_{3}\right), 3.09-3.22(\mathrm{dd}, J=27.5$, $21.8 \mathrm{~Hz}, 2 \mathrm{H}), 7.03(\mathrm{~s}, 1 \mathrm{H}, \mathrm{CH}), 7.31-7.39(\mathrm{~m}, 6 \mathrm{H}$, phenyl), 7.52-7.60 (m, 2H, phenyl), 8.30-8.40 (d, 2H, phenyl), $9.06\left(2 \mathrm{H}, \mathrm{NH}_{2}\right) .{ }^{13} \mathrm{C}-\mathrm{NMR}\left(100 \mathrm{MHz}, \mathrm{CDCl}_{3}\right) \delta$ (ppm): $11.48\left(\mathrm{CH}_{3}\right), 26.86\left(\mathrm{CH}_{3}\right), 44.7$ (cyclic $\left.\mathrm{CH}_{2}\right), 66.85$ (CH cyclic), $120.25(2 \mathrm{CH}), 125.7(\mathrm{CH}, \mathrm{C}), 126.5(2 \mathrm{CH}), 127.4(\mathrm{CH}, \mathrm{C}), 129.02(2 \mathrm{CH}), 129.8$ $(2 \mathrm{CH}), 131(\mathrm{C}), 138(\mathrm{C}), 141.60(\mathrm{C}), 155.80(\mathrm{C}), 156.27(\mathrm{C}), 165(\mathrm{C}), 178(\mathrm{C}=\mathrm{S})$. Anal. calcd. for $\mathrm{C}_{23} \mathrm{H}_{19} \mathrm{~N}_{7} \mathrm{~S}$ (425.5): C, 64.92; H, 4.50; N, 23.04. Found: C, 64.94; H, 4.44; N, 23.30\%.

2-Amino-4-(4-phenyl)-6-(3,6-dimethyl-1-phenyl-1H-pyrazolo[3,4-b]pyrazine-5-yl)pyrimidine (30): A mixture of chalcone $25 \mathrm{a}(7 \mathrm{mmol})$, guanidine sulfate $(0.12 \mathrm{~g}, 7 \mathrm{mmol})$ in ethanolic $\mathrm{KOH}(30 \%, 5 \mathrm{~mL})$ was heated under reflux for $3-4 \mathrm{~h}$. The reaction mixture was then evaporated to half volume and after cooling it was neutralized with dil. HCl. The solid precipitate was filtered off, washed with water, and recrystallized from dioxane-acetone mixture (1:3) as yellow crystals, yield $0.1 \mathrm{~g}(40 \%)$, m.p. $150-152{ }^{\circ} \mathrm{C}$. IR ( $($, $\mathrm{cm}^{-1}$ ): 3302, $3182\left(\mathrm{NH}_{2}\right), 3061.37$ (CH arom.), 2919, 2849 (CH aliph.). ${ }^{1} \mathrm{H}-\mathrm{NMR}\left(400 \mathrm{MHz}, \mathrm{CDCl}_{3}\right) \delta$ (ppm): $2.77\left(\mathrm{~s}, 3 \mathrm{H}, \mathrm{CH}_{3}\right), 2.99\left(\mathrm{~s}, 3 \mathrm{H}, \mathrm{CH}_{3}\right), 5.27\left(\mathrm{~d}, 2 \mathrm{H}, \mathrm{NH}_{2}\right), 7.34(\mathrm{t}, 3 \mathrm{H}$, phenyl), $7.53(\mathrm{t}, 3 \mathrm{H}$, phenyl), $7.67(\mathrm{~s}, 1 \mathrm{H}, \mathrm{CH}), 8.23\left(\mathrm{~d}, 2 \mathrm{H}\right.$, phenyl), 8.34-8.36 (d, 2H, phenyl). ${ }^{13} \mathrm{C}-\mathrm{NMR}\left(100 \mathrm{MHz}, \mathrm{CDCl}_{3}\right) \delta(\mathrm{ppm})$ : $11.11\left(\mathrm{CH}_{3}\right), 24.58\left(\mathrm{CH}_{3}\right), 107.81(\mathrm{C}), 119.92(\mathrm{CH}), 120.21(2 \mathrm{CH}), 125.86(\mathrm{CH}), 127.22(2 \mathrm{CH}), 128.77(2 \mathrm{CH})$, $129.14(2 \mathrm{CH}), 130.66(\mathrm{CH}), 132.31(\mathrm{C}), 137.40(\mathrm{C}), 139.23(\mathrm{C}), 142.91(\mathrm{C}), 144.02(\mathrm{C}), 146.52(\mathrm{C}), 152.54(\mathrm{C})$, 162.87 (C), 166.64 (C). Anal. calcd. for $\mathrm{C}_{23} \mathrm{H}_{21} \mathrm{~N}_{7}$ (395): $\mathrm{C}, 69.85 ; \mathrm{H}, 5.35 ; \mathrm{N}, 24.79$. Found: $\mathrm{C}, 69.63 ; \mathrm{H}$, $5.44 ; \mathrm{N}, 24.60 \%$.

\subsection{Biological Evaluations}

\subsubsection{Anti-Inflammatory Assay}

Adult albino rats, weighing 150-200 g, were divided into ten groups, each of three animals. The animals were allowed food and water ad libitum, except during the experiment. They were housed in a room at $23 \pm 2 \mathrm{C}$ with a $12 \mathrm{~h}$ light/dark cycle. All the compounds under test and the indomethacin reference drug [30], in 3\% Tween 80 solution in normal saline as a vehicle, were administered at a dose of $28 \mu \mathrm{M} / \mathrm{kg}$ bodyweight, while control group received only a vehicle. The difference between the thicknesses of the paw at zero time and different time intervals after injection was taken as a measure of edema. The measurement was carried out at $0.5,1,2,3$, and $4 \mathrm{~h}$ after injection of the tested compounds, reference drug, and control. The right paw volume was measured using a digital plethysmometer (Model 7150, Ugo Basile, Varese, Italy), directly before and after carrageenan injection to detect the carrageenan induced inflammation.

\subsubsection{Cytotoxicassay}

A number of $1 \times 10^{4}$ cells/well were cultured in 96-well plates and then incubated at $37{ }^{\circ} \mathrm{C}$, under conditions of $5 \% \mathrm{CO}_{2}$ and $95 \%$ air for $24 \mathrm{~h}$. On the following day, the compounds under test, diluted to the desired concentrations, were added to the wells with the respective negative control and then the cells were incubated for $24 \mathrm{~h}$. Next, $50 \mu \mathrm{L}$ of MTT (3-(4,5-dimethylthiazol-2yl)-2,5-diphenyl tetrazolium bromide) solution ( $2 \mathrm{mg} / \mathrm{mL}$ of MTT in PBS) was added to each well and left for 3-4 $\mathrm{h}$. Formazan crystals formed after incubation were dissolved in $150 \mu \mathrm{L}$ DMSO were added to each well. The 96-well plates were shaken for $10 \mathrm{~min}$ and then were read at A570 with reference filter at A650 using Elisa plate reader. Paclitaxel was used as a positive control.

\section{Conclusions}

In conclusion, several new derivatives of pyrazolo[3,4-b]pyrazines and related heterocycles were prepared and evaluated for their anti-inflammatory and anti-breast cancer MCF-7 cell line activities. Compounds 15 and 29 showed the higher anti-inflammatory activity, where the potency of the former compound was comparable to that of the indomethacin reference drug (cf. Table 1). On the other hand, compounds $25 \mathbf{i}$, 25j exhibited very significant anticancer activity against MCF-7 breast cancer cell line with respect to the positive control Paclitaxel (cf. Figures 1 and 2). 
Supplementary Materials: The spectral data are available online Figures S1-S111.

Author Contributions: Conceptualization, H.E.-K., T.E.-E., P.V. (Pierre Verhaeghe) and P.V. (Patrice Vanelle); Data curation, H.E.-K., P.V. (Pierre Verhaeghe) and P.V. (Patrice Vanelle); Formal analysis, T.E.-E.; Investigation, M.S.; Methodology, H.E.-K. and P.V. (Pierre Verhaeghe); Supervision, H.E.-K. and T.E.-E.; Validation, H.E.-K., P.V. (Pierre Verhraeghe) and P.V. (Patrice Vanelle); Writing-original draft, M.S.; Writing-review \& editing, H.E.-K. All authors have read and approved the final manuscript.

Funding: This research received no external funding.

Conflicts of Interest: The authors declare no conflict of interest.

\section{References}

1. Akahane, A.; Kuroda, S.; Itani, H.; Tabuchi, S.; Sato, Y.; Matsuoka, N.; Tada, M.; Matsuoka, H.; Oku Tanaka, T.A. Pyrazolopyrazines and Their Use as Adenosine Antagonists. Chem. Abstr. 2001, 135, 33489a.

2. Matsuoka, N.; Moriguchi, A.; Tada, M.; Mihara, T. Novel Use of Adenosine $\mathrm{A}_{1} \mathrm{~A}_{2 \mathrm{a}}$ Receptor Dual Antagonists. Chem. Abstr. 2000, 134, 533m.

3. Akahane, A.; Tanaka, A. Pyrazolopyrazine Compound and Pharmaceutical Use Thereof. Chem. Abstr. 2003, 138, 24732a.

4. Imaizumi, K.; Sado, T. Bone Metabolism Improvers Containing Pyrazolopyrazine. Chem. Abstr. 1994, $121,91797$.

5. Sado, T.; Inoue, A. Preparation of $1 H$-pyrazolo[3,4-blpyrazines as blood platelet aggregation inhibitors and anti-inflammatories. Chem. Abstr. 1990, 113, 78422k.

6. Abdelmohsen, S.A.; El-Emary, T.I.; El-Kashef, H. Synthesis, anti-inflammatory and antibacterial activities of novel pyrazolo[4,3-g]pteridines. Chem. Pharm. Bull. 2016, 64, 476-482. [CrossRef] [PubMed]

7. Takabe, F.; Shibayama, A.; Yanaguchi, M.; Yamaji, M.; Hanai, R.; Sadohara, H. Preparation of pyrazolopyridinones and analogs as herbicides. Chem. Abstr. 1997, 126, 277477a.

8. Suzuki, S.; Inoue, A. Anticancer agents containing $1 H$-pyrazolo[3,4-b]pyrazines. Chem. Abstr. 1990, $113,218276 \mathrm{t}$.

9. Suzuki, S. Preparation of 1,5-disubstituted-1H-pyrazolo[3,4-b]pyrazines as anticancer agents. Chem. Abstr. 1991, 114, 178382m.

10. Hofmann, J.; Sickerand, D.; Mann, G. Preparation of 1,3,5-trisubstituted-6-hydroxypyrazolo [3,4-b]pyrazines. Chem. Abstr. 1990, 113, 231409h.

11. Rangnekar, D.W.; Dhamnaskar, S.V. Synthesis of pyrazolo[4', $\left.3^{\prime}: 5,6\right]$ pyrazino[2,3-c] pyrazoles and pyrazolo $\left[4^{\prime}, 3^{\prime}: 5,6\right]$ pyrazino[2,3-d]pyrimidines and their application to polyester fibres. J. Chem. Technol. Biotechnol. 1990, 49, 311-320. [CrossRef]

12. El-Emary, T.I.; Kamal El-Dean, A.M.; El-Kashef, H.S. Facile synthesis of some new pyrazolo [3,4- $b$ ]pyrazines and their antifungal activity. Il Farmaco 1998, 53, 383-388. [CrossRef]

13. El-Kashef, H.S.; El-Emary, T.I.; Gasquet, M.; Timon-David, P.; Maldonado, J.; Vanelle, P. New pyrazolo [3,4-b]pyrazines: Synthesis and biological activity. Pharmazie 2000, 55, 572-576. [PubMed]

14. Suzuki, S.; Suzuki, K.; Honda, H. 1-Phenyl-1H-pyrazolo[3,4-b]pyrazine derivatives. Chem. Abstr. 1984, 100, $68319 \mathrm{z}$.

15. Svetlik, J. New condensed tri- and tetracyclic pyrazole ring system. Heterocycles 1984, 22, $2513-2516$. [CrossRef]

16. Farghaly, A.R.; Esmail, S.; Abdel-Zaher, A.; Hafez, A.A.; El-Kashef, H. Synthesis and anticonvulsant activity of some new pyrazolo[3,4-b]pyrazines and related heterocycles. Bioorg. Med. Chem. 2014, 22, 2166-2175. [CrossRef] [PubMed]

17. El-Emary, T.I. Synthesis and biological activity of some new pyrazolo[3,4-b] pyrazines. J. Chin. Chem. Soc. 2006, 53, 391-401. [CrossRef]

18. El-Emary, T.; El-Kashef, H. First synthesis and biological evaluation of indeno[2,1-e]pyrazolo [3,4-b]pyrazin-5-one and related derivatives. Eur. J. Med. Chem. 2013, 62, 478-485. [CrossRef] [PubMed]

19. Siegel, S.; Wilmen, A.; Roehrig, S.; Svenstrup, N.; Gnoth, N.; Heitmeier, M.J.; Rester, S. Preparation of Imidazopyrazines, Pyrazolopyrazines, and Imidazotriazines for Treatment of Hematologic Diseases. DE Patent 102007032349A1, 15 January 2009. 
20. Tasker, A.; Pettus, L.H.; Wurz, R. Pyrazolo[3,4- $b]$ pyrazine Compounds as p38 Modulators and Methods of Use as Anti-Inflamatory Agents. U.S. Patent 8367671B2, 5 February 2013.

21. Quiroga, J.; Sanchez, N.E.; Acosta, P.; Insuasty, B.; Abonia, R. Microwave-assisted synthesis of fused pyrazolo $[3,4-b]$ pyrazines by the reaction of ortho-aminonitrosopyrazoles and cyclic $\beta$-diketones. Tetrahedron Lett. 2012, 53, 3181-3187. [CrossRef]

22. Rangnekar, D.W.; Dhamnaskar, S.V. Synthesis of 5-hetarylpyrazolo[3,4-b]pyrazines and their use as disperse dyes for polyester fibres. Dyes Pigment. 1990, 13, 241-250. [CrossRef]

23. Gomes, M.N.; Muratov, E.N.; Pereira, M.; Peixoto, J.C.; Rosseto, L.P.; Cravo, P.V.L.; Andrade, C.H.; Neves, B.J. Chalcone derivatives: Promising starting points for drug design. Molecules 2017, 22, 1210. [CrossRef] [PubMed]

24. Mirossay, L.; Varinská, L.; Mojžiš, J. Antiangiogenic effect of flavonoids and chalcones: An update. Int. J. Mol. Sci. 2018, 19, 27. [CrossRef] [PubMed]

25. Kotha, R.R.; Kulkarni, R.G.; Garige, A.K.; Nerella, S.G.; Garlapati1, A. Synthesis and cytotoxic activity of new chalcones and their flavonol derivatives. Med. Chem. 2017, 7, 353-360. [CrossRef]

26. Champelovier, P.; Chauchet, X.; Hazane-Puch, F.; Vergnaud, S.; Garrel, C.; Laporte, F.; Boutonnat, J.; Boumendjel, A. Cellular and molecular mechanisms activating the cell death processes by chalcones: Critical structural effects. Toxicol. In Vitro 2013, 27, 2305-2315. [CrossRef] [PubMed]

27. Lipinski, C.F.; Oliveira, A.A.; Honorio, K.M.; Oliveira, P.R.; Ferreira da Silva, A.B. A molecular modeling study of combretastatin-like chalcones as anticancer agents using PLS, ANN and consensus models. Struct. Chem. 2018, 29, 957-965. [CrossRef]

28. Bhale, P.S.; Chavan, H.V.; Dongare, S.B.; Shringare, S.N.; Mule, Y.B.; Nagane, S.S.; Bandgar, B.P. Synthesis of extended conjugated indolyl chalcones as potent anti-breast cancer, anti-inflammatory and antioxidant agents. Bioorg. Med. Chem. 2017, 27, 1502-1507. [CrossRef] [PubMed]

29. Karthikeyan, C.; Moorthy, N.S.H.N.; Ramasamy, S.; Vanam, U.; Manivann, E.; Karunagaran, D.; Trivedi, P. Recent Patents on Anti-Cancer. Drug Discov. 2015, 10, 97-115.

30. Winter, C.A.; Risly, E.A.; Nuss, G.W. Carrageenin-induced edema in hind paw of the rat as an assay for antiinflammatory drugs. Proc. Soc. Exp. Biol. Med. 1962, 111, 544-547. [CrossRef] [PubMed]

31. Ismail, I.A.; Kang, H.S.; Lee, H.-J.; Chang, H.; Yun, J.; Lee, C.W.; Kim, N.H.; Kim, H.S.; Yook, J.I.; Hong, S.-H.; Kwon, B.-M. 2-Hydroxycinnamaldehyde inhibits the epithelial-mesenchymal transition in breast cancer cells. Breast Cancer Res. Treat. 2013, 137, 697-708. [CrossRef] [PubMed]

Sample Availability: Samples of the compounds $\mathbf{2 5 a}-\mathbf{k}$ are available from the authors.

(C) 2018 by the authors. Licensee MDPI, Basel, Switzerland. This article is an open access article distributed under the terms and conditions of the Creative Commons Attribution (CC BY) license (http:/ / creativecommons.org/licenses/by/4.0/). 